\title{
CONTRIBUIÇÃO AO ESTUDO DO CLIMA URBANO EM UBERABA (MG)
}

\author{
SANCHES, Fabio de Oliveira - fsanches.73@gmail.com \\ Universidade Federal de Juiz de Fora / UFJF
}

FERNANDES, Enágio - enagiofernandes@live.com
Universidade Federal do Triangulo Mineiro / UFTM

FERREIRA, Ricardo Vicente - rcrdvf@gmail.com

Universidade Federal do Triangulo Mineiro / UFTM
FIRMINO, Glauber Verner - glauberverner@gmail.com Universidade Federal do Triangulo Mineiro / UFTM
ALVES, Matheus Oliveira - matheus_cefetiano@hotmail.com Universidade Federal do Triangulo Mineiro / UFTM

\begin{abstract}
RESUMO: Estudos mostram que o efeito da "ilha de calor urbana" ocorre quando, em decorrência modificações das características físicas das superfícies, resultante da substituição de áreas verdes por edificações e pavimentação, ocorre o aumento da temperatura do ar nas áreas centrais das cidades em relação as áreas mais afastadas do centro. O presente artigo tem como objetivo comparar as temperaturas do ar em quatro sítios (locais) representativos da cidade de Uberaba (MG) buscando verificar se existem diferenças significativas em função do tipo de construção e de pavimentação no seu entorno. Foram utilizados dados de temperatura do ar da Estação Meteorológica do INMET, da estação meteorológica do Aeroporto de Uberaba e dados coletados por meio de termohigrômetros digitais no centro da cidade e no bairro Boa Vista. A coleta dos dados foi feita em todos os meses do ano de 2016, durante 10 dias interruptos (do dia 20 ao dia 29), nos três horários sinóticos (9h; 15h; $21 \mathrm{~h}$ horário local). Inicialmente, os dados dos quatro sítios foram submetidos à Análise de Variância (ANOVA) para verificar se houve variação significativa entre eles e, ao Teste de Tukey para identificação do (s) sítio (s) que variou (aram) em relação aos demais. Por interpretação visual de imagem do Google Maps, acessada pelo Sistema de Informação Geográfica QGIS, os tipos de revestimentos e cobertura vegetal urbana foram mapeados em um raio de 100 metros no entorno de cada sítio de coleta de dados. Os resultados da estatística (ANOVA e Tukey) revelaram que as temperaturas do centro da cidade e do bairro Boa Vista foram, significativamente, superiores aos dados de temperatura do Aeroporto e do INMET na maior parte dos meses do ano analisado. O processamento da imagem de satélite demonstrou que a maior parte da superfície no entorno dos sítios central e do bairro Boa Vista são constituídos por áreas edificadas (altas e baixas) e com baixa densidade de vegetação quando comparadas aos outros dois sítios de coleta de dados (INMET e Aeroporto). Dessa forma, a partir dos resultados encontrados, foi possível concluir que o tipo de uso e de ocupação do solo urbano são os responsáveis pela ocorrência temperaturas mais elevadas na região central e no bairro Boa Vista, em relação as demais localidades analisadas na cidade de Uberaba (MG).
\end{abstract}

PALAVRAS-CHAVE: Ilha de Calor Urbano, ANOVA, Teste de Tukey, Testes estatísticos, Triângulo Mineiro.

\section{CONTRIBUTION TO THE URBAN CLIMATE STUDY OF UBERABA (MG)}

ABSTRACT: Studies have shown that "urban heat island" effect occurs when, due to changes on physical characteristics of surfaces, resulting from replacement of green spaces by edifications and pavement, occurs air temperature raise on central spaces in cities if compared to farthest areas from center. The following article has the objective of compare air temperatures on four representative sites (places) of Uberaba (MG), aiming to verify the existence of significant differences in function of its surrounding buildings 
and pavements. The study used air temperature data of INMET's Meteorological Station, Uberaba's Airport Meteorological Station and data collected by digital thermohygrometers on downtown and in Boa Vista's neighborhood. Data collection happened on every month of 2016, during 10 interrupt days (from 20th to 29th), on synoptic times (9h; 15h; 21h local time). Firstly, the four sites data were submitted to Analysis of Variance (ANOVA) to verify the occurrence of significant variation among them and to Tukey's Test to identify which sites varied from the others. For visual interpretation of Google Maps' images, accessed on Quantum Geographic Information System software environment, kinds of coverture were mapped on a 100 meters ray surrounding each data collection site. The statistical results (ANOVA and Tukey's Test) revealed that downtown's and Boa Vista neighborhood's temperature were significantly superior than Airport's and INMET's temperature data on most of the months analyzed. Satellite image processing showed that most part of downtown's and Boa Vista's sites surrounding surface were constituted by built-up areas (high or low edifications) and low vegetal coverture if compared to the other two data collection sites (INMET and Airport). Thus, from the found results, it is possible to conclude that the kinds of urban soil coverture and occupation are the responsible for higher temperatures occurrence on downtown and Boa Vista neighborhood when compared to the other analyzed locations on the city of Uberaba (MG)

KEYWORDS: Urban Heat Island, ANOVA, Tukey's Test, Statistical Tests, Triângulo Mineiro

\section{INTRODUÇÃO}

No Brasil, o processo de urbanização se constitui como um fenômeno que se desenvolveu de maneira significativa, a partir da segunda metade do século $X X$, estimulado pela modernização da economia e pelo incremento do setor industrial (NASCIMENTO, 1995). Tal processo foi o responsável pelo aumento da população urbana no decorrer da segunda metade do século XX levando, em meados da década de 1960, a uma inversão nos valores percentuais entre a população rural e a urbana (IBGE, 2006).

A partir da década seguinte (1970) as cidades brasileiras passaram a adquirir cada vez mais características urbanas. O processo de urbanização se acelerou, resultando, atualmente, em uma taxa de urbanização em torno de 84\%, segundo o Censo de 2010 (http://seriesestatisticas.ibge.gov.br).

Sob a perspectiva dos efeitos da urbanização e do crescimento urbano para a climatologia, o acelerado processo de expansão sofrido pelas cidades, muitas vezes desprovidas de um devido planejamento territorial, contribuiu para transformações na paisagem urbana que impactaram profundamente no balanço de energia, na interação entre os elementos urbanos (casas, ruas, avenidas, edifícios, parques, galpões etc.) e as camadas superficiais atmosféricas.

Monteiro (1976) e Monteiro e Mendonça (2011) já alertavam que essas transformações ocorridas nas cidades levariam a formação de um clima próprio (o clima urbano), o qual seria o resultado da interferência de todos os fatores que atuam sobre a camada limite urbana e que operariam de modo a modificar - clima local, originando uma atmosfera local com características climáticas típicas, ou seja, temperatura e umidade relativas do ar diferentes das verificadas nas áreas circunvizinhas.

Seus efeitos poderiam ser observados de forma mais direta através de manifestações ligadas ao conforto térmico na configuração de "ilhas de calor", aos impactos pluviais na ocorrência de enchentes na área urbana e à qualidade do ar com a poluição atmosférica. 
Nessa mesma perspectiva, Oke (1987) afirma que

O processo de urbanização produz mudanças radicais na natureza das superfícies e das propriedades atmosféricas de uma região. Envolvendo, assim, as características de radiação, de temperatura, de umidade e da aerodinâmica e altera, pois, os balanços naturais hidrológico e solar. Por exemplo, o aparentemente inevitável aumento da poluição atmosférica afeta a transferência de radiação e fornece cargas extras aos núcleos nos quais as gotas de chuva se formam; os materiais de construções urbanas densas aumentam a retenção de calor e a impermeabilidade do sistema; a geometria em paralelepípedos possibilita a retenção de radiação e a estagnação atmosférica, além de prover maior rugosidade à superfície; o calor e a água dejetados como produtos do desperdício das atividades humanas suplementam os recursos naturais de água e calor.

Assim, a partir dessa problemática, Monteiro (1976) propôs a Teoria do Sistema Clima Urbano (SCU), com o objetivo de compreender e explicar as relações entre tais variáveis com base na meteorologia local e regional, englobando os aspectos de urbanização como crescimento da população e expansão das cidades, materiais utilizados nas construções e revestimento das pavimentações, verticalização do solo, conforto e bem-estar do cidadão, morfologia urbana etc.

Corroborando com as ideias de Oke (op cit) e Monteiro (op cit), Lombardo (1984, p. 22) esclarece que o:

Clima urbano é um sistema que abrange o clima de um dado espaço terrestre e sua urbanização. É um mesoclima que está incluído no macroclima e que sofre, na proximidade do solo, influências microclimáticas derivadas dos espaços urbanos. Pode-se analisar as variações do ambiente urbano, nos vários níveis, tais como bairros, ruas, casas, ambientes internos. A ação ecológica natural, associada aos fenômenos urbanos, constitui o conjunto complexo de inter-relações que produzem o clima urbano.

Dessa forma, as alterações dos elementos climáticos que compõem a atmosfera local ocorrem devido às propriedades que compõem a dinâmica do aglomerado urbano, associadas aos tipos e níveis de adensamento e uso que revestem 0 solo. A partir dessas modificações formam-se anomalias na temperatura e na umidade, criando fenômenos como as "ilhas de calor urbanas" (ICU).

Para Oke (1987), o fenômeno de ilha de calor irá ocorrer, pois as propriedades de armazenamento e dispersão de calor dos materiais de construção contribuem para o acúmulo de calor durante o dia na cidade e para sua devolução para a atmosfera durante a noite. Dessa forma, o efeito da "ilha de calor urbana" ocorre, devido ao aumento da temperatura do ar nas áreas centrais das cidades, em comparação as regiões mais afastadas, decorrente das modificações das características térmicas das superfícies, resultante da substituição de áreas verdes por edificações e pavimentação. 
Reboita et al (2015) afirmam que áreas com cobertura vegetal tendem a usar a energia recebida do Sol na evapotranspiração, enquanto que áreas de solo descoberto e urbanizadas utilizam essa energia para se aquecer, impactando diretamente a variação diurna da temperatura do ar. Dessa forma, as diferentes coberturas da superfície terrestre possuem diferentes valores de albedo o que influencia o clima de cada local.

No Brasil, trabalhos utilizando diversas técnicas têm sido desenvolvidos sob a temática do clima urbano na identificação das ilhas de calor: transectos móveis (AMORIM, 2005; ROCHA e FIALHO, 2010; ANJOS et al., 2013; COLLISCHONN, 2016), comparação entre estações em ambiente urbano e ambiente rural (ROCHA e FIALHO, 2010; ANDRADE et al., 2013; MARIANO e ROCHA, 2016), estações fixas em diferentes padrões de uso e ocupação em ambiente urbano (TARIFA e ARMANI, 2001; COLLISCHONN et al., 2015; FERREIRA, 2014; NOBREGA et al., 2016), utilizando técnicas estatísticas (ANDRADE et al., 2013; ALVES, 2017), interpolando dados por meio de geoestatística (MAGALHÃES FILHO e ABREU, 2010; ANDRADE et al., 2010; ANJOS et al., 2013; FERREIRA, 2014; BARROS e LOMBARDO, 2016; MACHADO e ASSIS, 2016; ALVES, 2017), utilizando técnicas de sensoriamento remoto (LOMBARDO, 1984; MENDONÇA, 1995; MENDONÇA e DUBREUIL, 2005; MOREIRA e GALVINCIO, 2007; FERREIRA, 2014; AMORIM et al., 2015; BARROS e LOMBARDO, 2016; ALVES, 2017) entre outros.

Sendo assim, o presente trabalho tem como objetivo analisar as temperaturas superficiais o ar em quatro sítios representativos da cidade de Uberaba (MG), analisando-os sob uma perspectiva estatística e de análise superficial, a fim de verificar a existência do fenômeno da "ilha de calor".

\section{MATERIAL E MÉTODOS}

\section{1 ÁREA DE ESTUDO}

De acordo com o IBGE (2016), Uberaba-MG destaca-se como o oitavo município do Estado de Minas Gerais em número de habitantes, com população estimada de 322.126 habitantes em 2016. Sua mancha urbana configura-se como um centro adensado, com muitas edificações e uma periferia caracterizada por uma descontinuidade no que se refere a cobertura do solo por construções e vazios urbanos (Figura 1 ). 


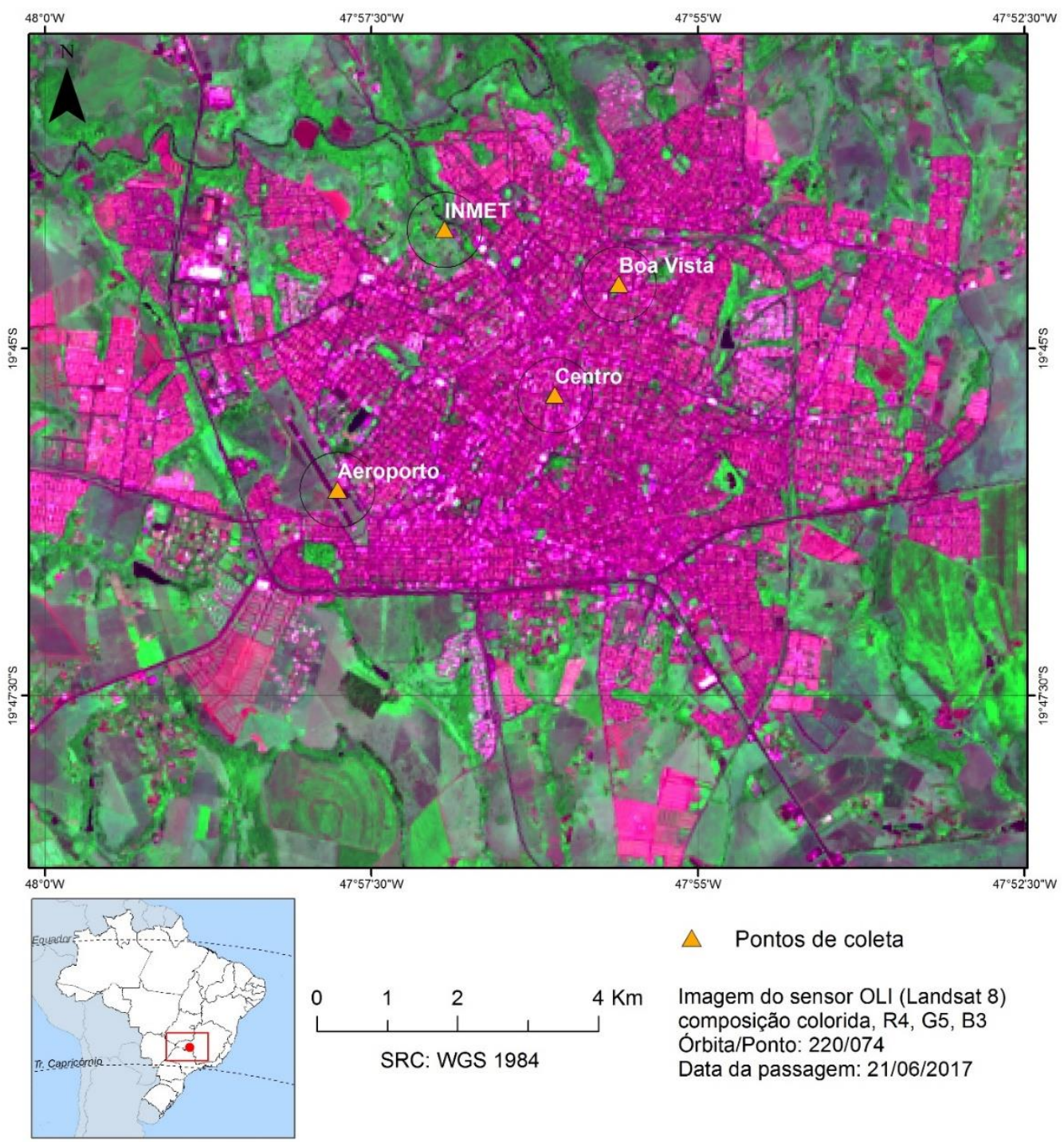

Figura 1 - Mancha urbana da cidade de Uberaba, visualizada através da combinação falsa cor dos filtros Red; Green; Blue, sobre as bandas Red (640-690 nm); NIR (850-880 $\mathrm{nm})$; Green (530-590nm), respectivamente. Destaque para a localização dos pontos de coleta de dados da pesquisa.

Segundo o sistema de classificação climática proposto por Köppen, o clima predominante na região é o tipo Aw (Savana Tropical), com temperatura média anual variando de $22^{\circ} \mathrm{C}$ a $26^{\circ} \mathrm{C}$ e as precipitações pluviométricas anuais, entre $1.100 \mathrm{~mm}$ a $1.750 \mathrm{~mm}$ (SÁ JUNIOR, 2009; NOVAIS, 2011). Uma das características mais marcantes dessa "tropicalidade" é a existência de duas estações hidrológica definidas: uma chuvosa (de outubro a março) e outra seca (de abril a setembro) (ALVES et al., 2005).

A superfície urbanizada (mancha urbana) medida sobre a imagem de satélite retornou uma área de cerca de $75 \mathrm{~km}^{2}$. Segundo Ferreira et al. (2015), essa superfície é caracterizada por processos de verticalização em sua área 
central e expansão urbana horizontal como consequências do processo de crescimento econômico e demográfico sofrido nos últimos anos.

\subsection{DADOS, TÉCNICAS E ANÁLISE}

Para o presente trabalho foram utilizados dados de temperatura do ar para quatro sítios representativos na cidade de Uberaba: a) Estação Meteorológica de Superfície do INMET (OMM: 83577); b) Aeroporto Mário de Almeida Franco (Aeroporto Municipal de Uberaba); c) Centro da cidade (UFTM Unidade Urbano Salomão); d) bairro Boa Vista (bairro residencial) conforme mostra a Tabela 1 e a Figura 1.

Tabela 1 - Coordenadas geográficas e altitude dos sítios de coleta de dados em Uberaba

\begin{tabular}{llll}
\hline Sítio & Latitude (S) & Longitude (W) & Altitude (m) \\
\hline INMET (OMM 83577) & $19^{\circ} 44^{\prime} 14.0^{\prime \prime}$ & $47^{\circ} 56^{\prime} 59.0^{\prime \prime}$ & 737 metros \\
Aeroporto & $19^{\circ} 45^{\prime} 57.7^{\prime \prime}$ & $47^{\circ} 57^{\prime} 44.3^{\prime \prime}$ & 812 metros \\
Centro (UFTM) & $19^{\circ} 45^{\prime} 20.0^{\prime \prime}$ & $47^{\circ} 56^{\prime} 04.0^{\prime \prime}$ & 769 metros \\
Boa Vista (bairro) & $19^{\circ} 44^{\prime} 32.0^{\prime \prime}$ & $47^{\circ} 55^{\prime} 36.5^{\prime \prime}$ & 778 metros \\
\hline
\end{tabular}

As temperaturas foram coletadas simultaneamente obedecendo aos horários sinóticos em função da disponibilidade dos dados da estação meteorológica do INMET: 9h, 15h, 21h (hora local) entre os dias 20 e 29, durante todos os meses do ano de 2016.

Os dados da estação do INMET foram obtidos a partir do site (www.inmet.gov.br) e os dados do Aeroporto de Uberaba, obtidos por meio do site www.airmetar.com.br. Este site disponibiliza, gratuitamente, informações meteorológicas dos principais aeroportos brasileiros.

Já os dados dos sítios Centro (UFTM) e Boa Vista (bairro) foram coletados utilizando dois termohigrômetros portáteis, digitais da marca Instrutherm, modelo HT-300, devidamente calibrados com os dados da Estação do INMET.

Após a coleta e organização, os dados respectivos a cada horário foram submetidos à aplicação da Análise de Variância (ANOVA) para verificação de possíveis diferenças estatísticas significativas entre os postos nos mesmos horários.

A ANOVA consiste em um teste que avalia se as médias ( $\mu 1$ e $\mu 2)$ e as variâncias ( $\sigma 1$ e $\sigma 2$ ) de duas ou mais amostras populacionais de dados são iguais, em resposta a diferentes níveis de fatores (SPIEGEL, 1993). Nesse trabalho foi adotado a ANOVA com fator único para a análise das temperaturas nos três horários de coleta para os quatro sítios de dados.

Para cada conjunto de dados, foi adotada a hipótese nula $\left(H_{0}\right)$ onde todas as médias e suas variâncias são, estatisticamente, iguais $\left(\mu_{1}=\mu_{2}\right.$ e $\left.\sigma_{1}=\sigma_{2}\right)$ em detrimento da hipótese alternativa $\left(H_{1}\right)$, onde há diferença, significativa, entre os valores médios e suas variâncias $\left(\mu_{1} \neq \mu_{2}\right.$ e $\left.\sigma_{1} \neq \sigma_{2}\right)$.

Ao comparar as médias de diferentes populações (conjunto de dados) verificando se suas médias são iguais ou não, a ANOVA permite que vários grupos sejam comparados ao mesmo tempo. 
Inicialmente calculou-se a dispersão entre os grupos $\left(S_{E}^{2}\right)$ por meio da equação (1):

$$
S_{\bar{x}}^{2}=\left[\frac{\sum \bar{x}_{l}^{2}-\frac{\left(\sum \bar{x}_{l}\right)^{2}}{k}}{k-1}\right]
$$

Onde $k$ representa os grupos, $k-1$ o grau de liberdade e $\bar{x}$ a média dos dados.

O passo seguinte consistiu em se determinar a dispersão dentro dos grupos $\left(S_{\bar{D}}^{2}\right)$. Para isso, utilizou-se a equação (2):

$$
S_{\bar{D}}^{2}=\left[\frac{\left(N_{1}-1\right) \cdot S_{1}^{2}+\left(N_{2}-1\right) \cdot S_{2}^{2}+\left(N_{3}-1\right) \cdot S_{3}^{2}+\left(N_{4}-1\right) \cdot S_{4}^{2}}{\left(N_{1}-1\right)+\left(N_{2}-1\right)+\left(N_{3}-1\right)+\left(N_{4}-1\right)}\right]
$$

Onde $N$ equivale ao número de grupos.

Já, a aplicação da estatística F foi dada pela equação (3):

$$
F=\frac{S_{E}^{2}}{S_{D}^{2}}
$$

Após a aplicação da ANOVA, e a partir os resultados do teste $F$ de Fischer, podemos considerar que, se o resultado da estatística $\mathrm{F}$ for superior ao valor do resultado do $\mathrm{F}$ Crítico (valor máximo aceitável para homogeneidade dos dados) concluiremos que existe variância significativa entre os conjuntos amostrais (H1).

Por sua vez, para se identificar qual sítio variou em relação aos demais sítios, aplicou-se o Teste de Tukey (TT) nos conjuntos de dados que se mostraram significativos a partir os resultados da ANOVA (ROGERSON, 2012).

O Teste de Tukey consiste em um teste de comparação de médias, muito rigoroso e de fácil aplicação, sobretudo para conjuntos amostrais relativamente pequenos. Esse teste tem como base a Diferença Mínima Significativa (DMS) entre as médias.

Foi possível identificar a DMS por meio ad equação (4):

$$
D M S=q_{\alpha}(k, k-1) \cdot \sqrt{\frac{Q M E}{n}}
$$

Onde: $q$ é o valor tabelado (Tabela de Tukey), QME é o quadrado médio dos resíduos e $n$ é o número de réplicas do nível. 
Para esse trabalho, os procedimentos de aplicação da ANOVA foram desenvolvidos utilizando a ferramenta "análise de dados" do software Excel (Microsoft Co.). Já, na aplicação do Teste de Tukey foi utilizado o software PAST (HAMMER et al., 2001).

Por fim, para a análise espacial do entorno de cada sítio utilizado neste trabalho foi adotado um raio de 100 metros conforme sugerem os trabalhos desenvolvidos por Hasenack (1989) e Oke (2016). Para os autores, essa área $\left(31.400 \mathrm{~m}^{2}\right)$ é capaz de influenciar diretamente as condições térmicas locais.

O cálculo da área dessa circunferência é dado a partir da seguinte equação (5):

$$
\text { Área: } 2 \cdot \pi \cdot r^{2}
$$

Onde $r$ corresponde ao raio da circunferência (100 metros) e $\Pi$ o comprimento de uma circunferência $(3,1416 \ldots)$.

A caracterização do uso e ocupação do espaço de entorno de cada sítio amostral foi feita utilizando o Sistema de Informação Geográfica QGIS, o qual utiliza imagens orbitais atualizadas do sistema Google Earth. Para este trabalho a imagem da cidade de Uberaba foi atualizada no mês de abril de 2016.

Nesse raio de 100 metros foram identificados os seguintes tipos de uso e ocupação: cobertura vegetal arbórea, cobertura vegetal arbustiva ou gramínea, capeamento asfáltico, edificação (casas, prédios, galpões etc.), corpos d'água e solo exposto.

\section{RESULTADOS E DISCUSSÃO}

\subsection{ESTATÍSTICA DOS DADOS}

Considerando os dados coletados para o mês de janeiro, a Figura 3 monstra o padrão de distribuição representado por meio da técnica do box plot.

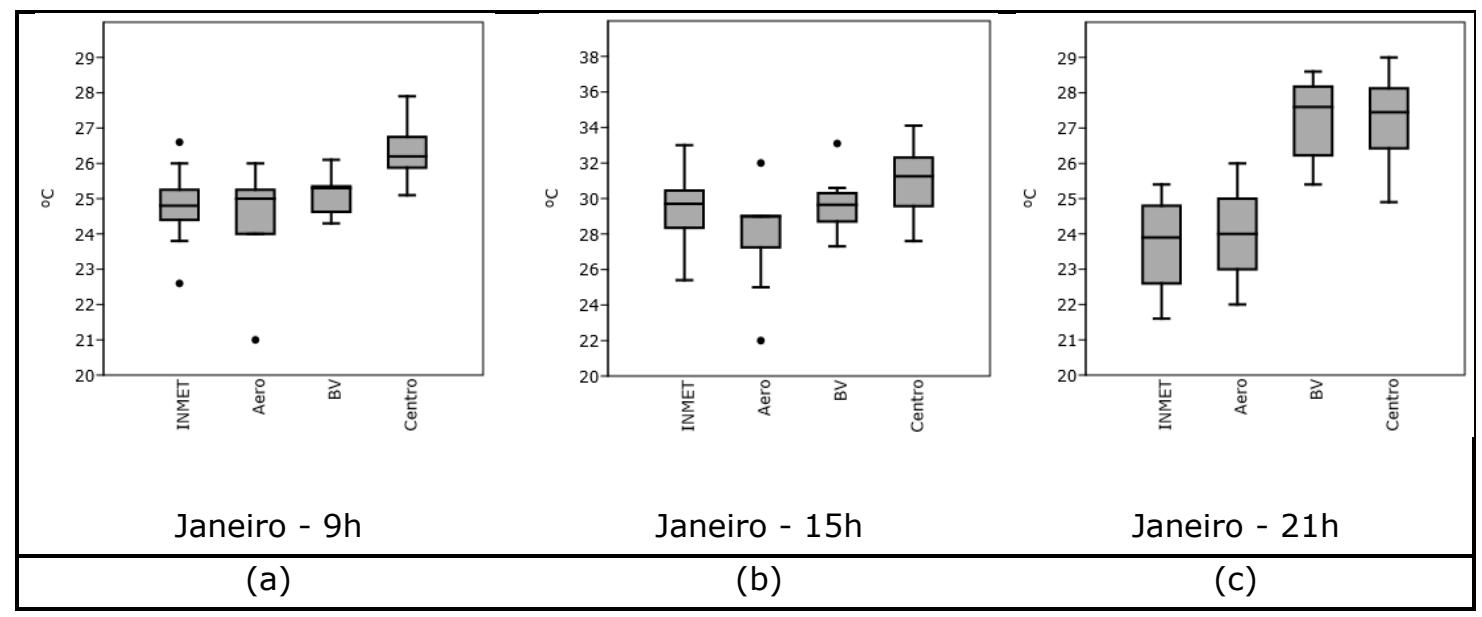

Figura 2 - Gráficos box plot para as temperaturas no mês de Janeiro 
A partir da aplicação da ANOVA (Tabela 2), os resultados dos valores de $\mathrm{F}$ para os três horários foram superiores ao $\mathrm{F}$ Crítico, demonstrando que os dados apresentam significância estatística para variância.

A aplicação do Teste Tukey (Tabela 3 ) revelou que às $9 \mathrm{~h}$, os dados do Centro variaram, significativamente, em relação aos demais sítios (Figura 3a). Para as $15 \mathrm{~h}$, o teste demonstrou que a variação foi significativa apenas para os dados do Centro em relação aos do Aeroporto (Figura 3b). Já, para as 21h, (Figura 3c), o teste considerou significativa a variação dos dados do Boa Vista e do Centro em relação aos dados do INMET e do Aeroporto.

Acredita-se que neste caso, para os dados de janeiro às $21 \mathrm{~h}$, mesmo sendo considerado um mês com temperaturas elevadas, o efeito do espaço urbano construído, tenha sido o responsável pelas temperaturas mais elevadas na área central da cidade e no bairro em relação ao entorno do aeroporto e da estação do INMET.

Em relação aos dados de fevereiro (Figura 4a), observa-se, claramente, que as temperaturas das áreas central e do bairro Boa Vista estiveram acima do padrão dos dados do Aeroporto e da estação do INMET. Já, no gráfico das temperaturas das 21h (Figura 4c), observa-se que os dados do Aeroporto estiveram abaixo dos demais postos, sobretudo, dos dados do bairro Boa Vista e do Centro.

A aplicação da ANOVA e do Teste de Tukey (Tabelas 2 e 3) confirmaram as análises para o mês de fevereiro. O Teste de Tukey considerou significância estatística ( $\mathrm{H} 1$ ) para o conjunto dos dados das $9 \mathrm{~h}$ e das $21 \mathrm{~h}$. De acordo com o resultado do teste, a temperatura dos sítios Central e do Boa Vista apresentaram significância em relação as temperaturas do INMET e do Aeroporto para o horário as $9 \mathrm{~h}$, bem como os dados das $21 \mathrm{~h}$ do Centro e do Boa Vista em relação aos do Aeroporto. Os dados da $15 \mathrm{~h}$ não apresentaram resultados estatisticamente significativos.

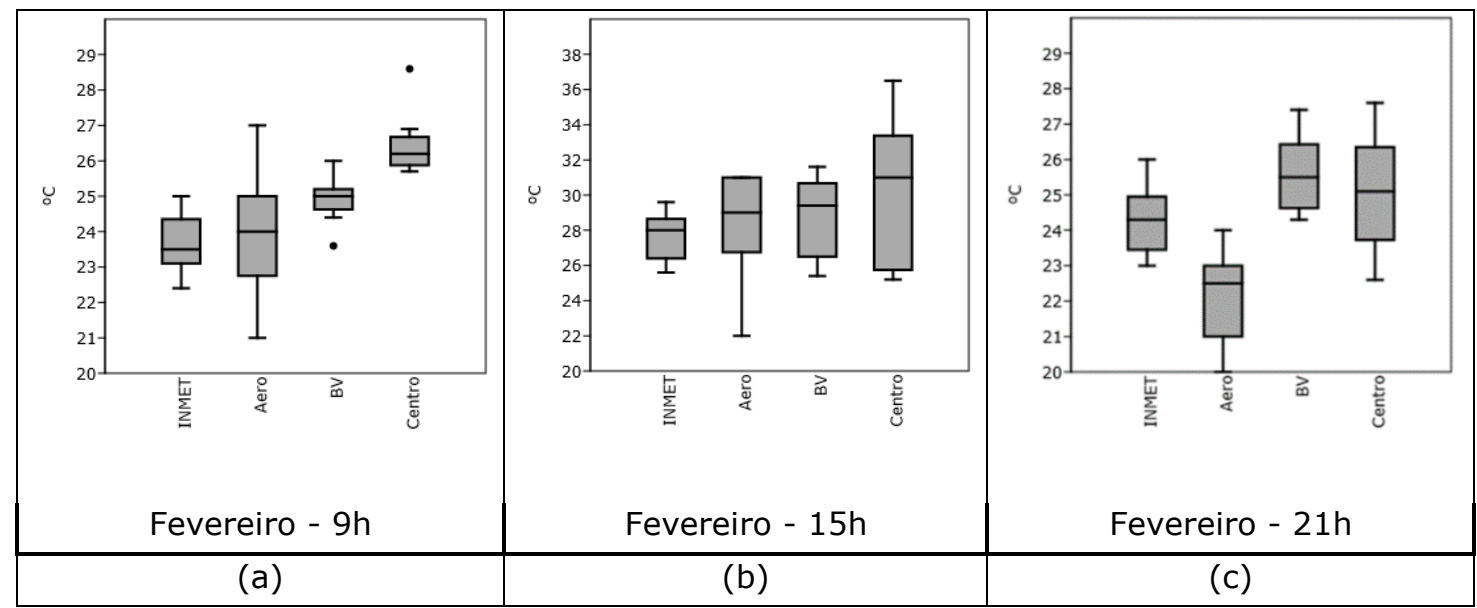

Figura 3 - Gráficos box plot para as temperaturas no mês de Fevereiro

A análise dos dados do mês de março (Figura 5) sugere, claramente, que Centro de Uberaba apresentou temperaturas mais elevadas que os demais sítios 
analisados. Tal fato é confirmado a partir dos resultados da ANOVA e do Teste de Tukey aos conjuntos de dados.

De acordo com os testes, para os dados das 9h, o Centro de Uberaba demonstrou valores significativamente superiores aos demais sítios (INMET, Aeroporto e Boa Vista) (Tabela 3 e Figura 5a).

No horário das $15 \mathrm{~h}$, dada à acentuada amplitude térmica, condição típica da estação do Outono no mundo tropical, os dados dos sítios INMET, Boa Vista e Centro apresentaram-se com uma distribuição normal similar, a qual, de acordo com a ANOVA, foram considerados estatisticamente homogêneos $\left(H_{0}\right)$.

A exceção foi observada nos dados do Aeroporto, os quais se mostraram estatisticamente diferentes em relação aos dados do Centro. É possível que essa diferença significativa entre os dados do Centro em relação aos dados do Aeroporto (Figura 5b) tenha se dado em virtude do Aeroporto localizar-se no topo de uma colina e, portanto, sujeito a ação dos ventos mais intensos nessa época do ano.

Já, em relação aos dados das $21 \mathrm{~h}$, a ANOVA e o Teste de Tukey consideraram os dados do Boa Vista e do Centro significativamente diferentes dos dados do Aeroporto e do INMET (Tabelas 2 e 3). A Figura $5 c$ permite visualizar, graficamente, tais diferenças por meio de suas distribuições e elevadas medianas. É possível atribuir essas diferenças térmicas aos materiais constituintes do espaço urbano nessas áreas (concreto, asfalto, edificações, áreas verdes reduzidas etc.), uma vez que tais materiais possuem inércia térmica mais lenta, influenciando na temperatura superficial do ar.

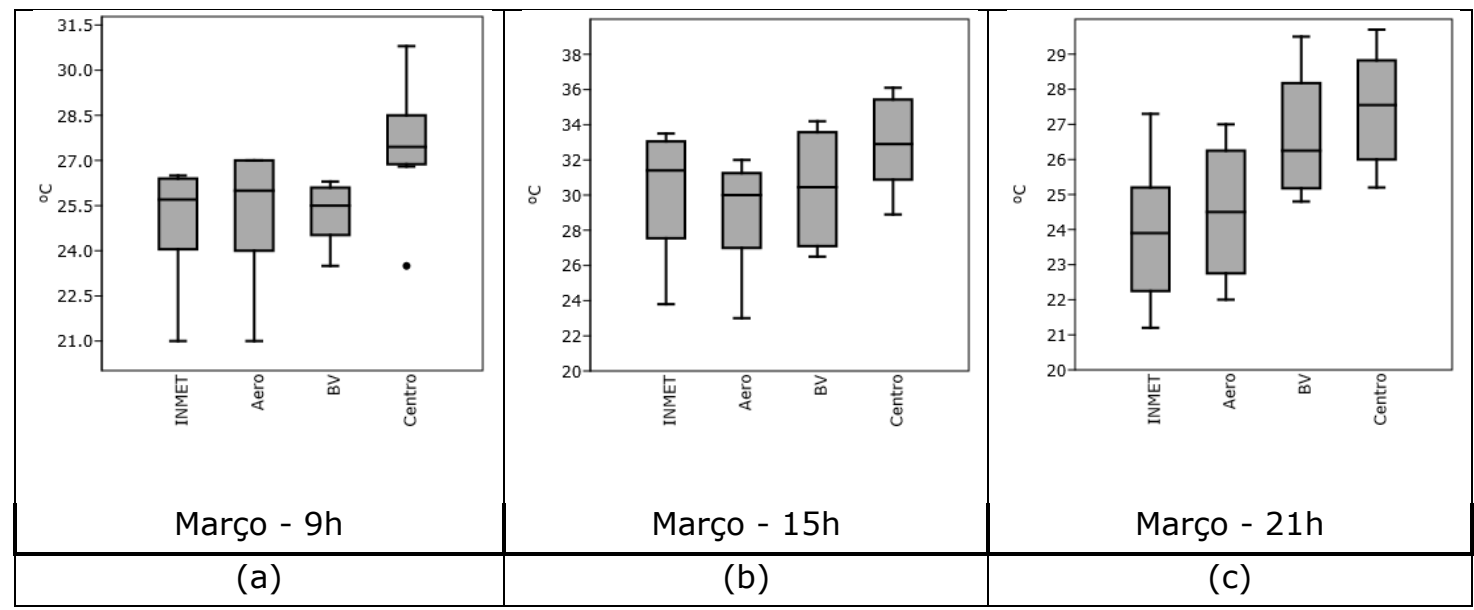

Figura 4 - Gráficos box plot para as temperaturas no mês de Março

Os gráficos dos meses de abril (Figura 6a, 6b e 6c) reforçam uma das principais características dos tipos de tempo na estação do Outono: a acentuada amplitude térmica diária. Os gráficos dos três horários mostram forte amplitude entre os valores máximo e mínimo, uma concentração dos dados no $3^{\circ}$ quartil e medianas muito elevadas. Tais características foram similares em todos os sítios analisados no mês de abril levando a aceitação da hipótese nula (HO) na aplicação da ANOVA. 
Nos dados do mês de maio, embora as características do outono não sejam tão similares as observadas nos dados de abril, verifica-se, ainda, os efeitos da amplitude térmica (diferença entre os valores máximos e mínimos). No entanto, os gráficos (Figuras $6 \mathrm{~d}$, $6 \mathrm{e}$ e $6 \mathrm{f}$ ) revelam que as medianas estiveram muito próximas entres os sítios analisados, nos três horários observados.

Os resultados da ANOVA e do Teste de Tukey confirmam a hipótese nula (H0) e consideram que as temperaturas dos quatro sítios analisados variaram de forma similar nos três horários de registro.

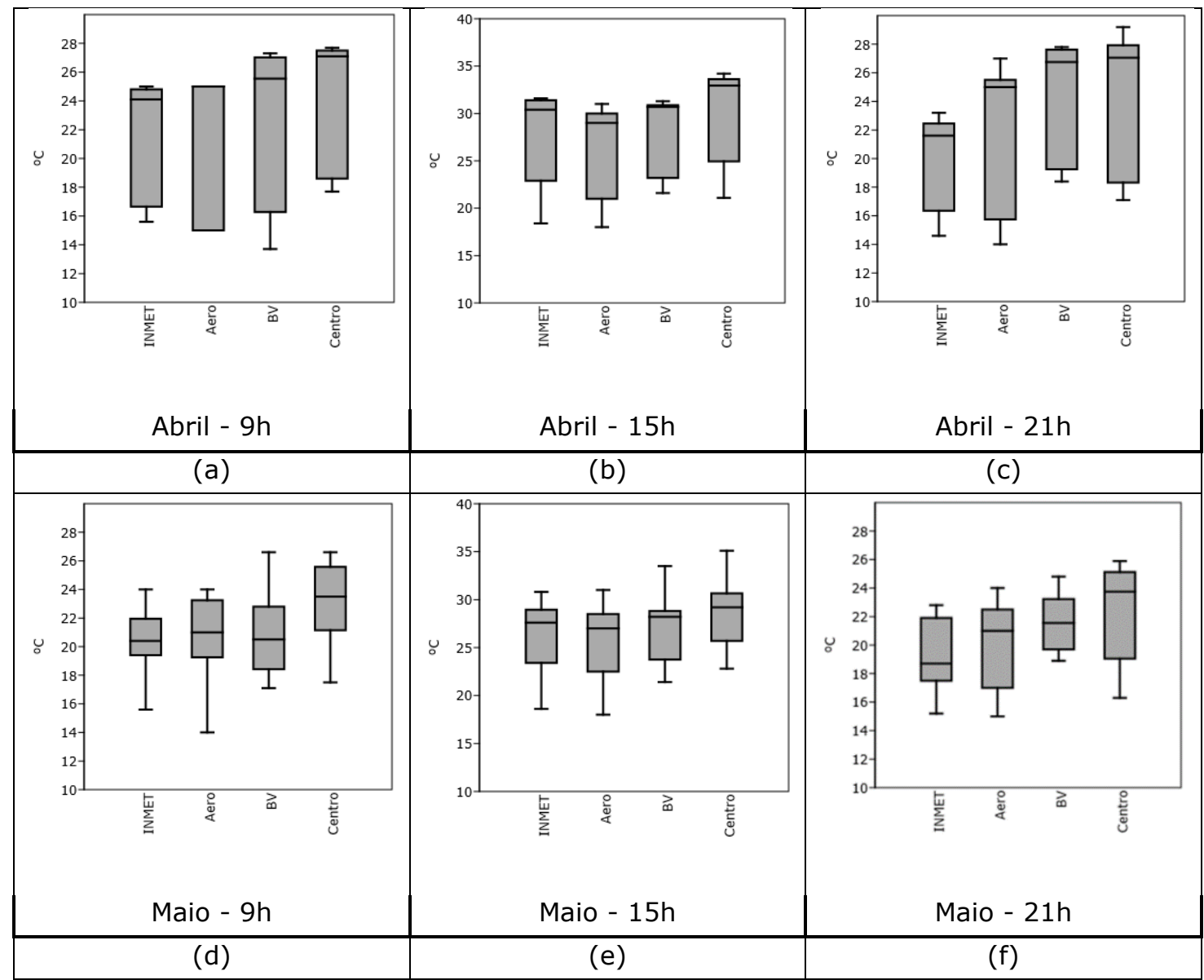

Figura 5 - Gráficos box plot para as temperaturas nos meses de Abril e Maio.

Acredita-se que os dados do mês de junho (Figura 7) sejam os que melhor representam os efeitos do espaço urbano construído nas temperaturas superficiais. As diferenças nos dados dos sítios Boa Vista e Centro em relação aos sítios Aeroporto e INMET são graficamente visíveis.

Os resultados da aplicação da ANOVA e do Teste de Tukey (Tabelas 2 e 3) nas temperaturas das $9 \mathrm{~h}$ consideraram que os dados do Boa Vista e Centro variaram, significativamente, em relação aos dado do Aeroporto e INMET. Na estatística das 15h, Boa Vista e Centro variaram em relação ao Aeroporto e, nos dados das 21h, os resultados foram ainda mais significativos: Aeroporto, Boa Vista e Centro variaram de forma significativa em relação aos dados do INMET e, os dados do Centro variaram em relação aos do Aeroporto. 
Acredita-se que a baixa umidade do ar do inverno, aliada as condições de uso e ocupação do espaço urbano tenha contribuído para as diferenças fossem mais significativas.

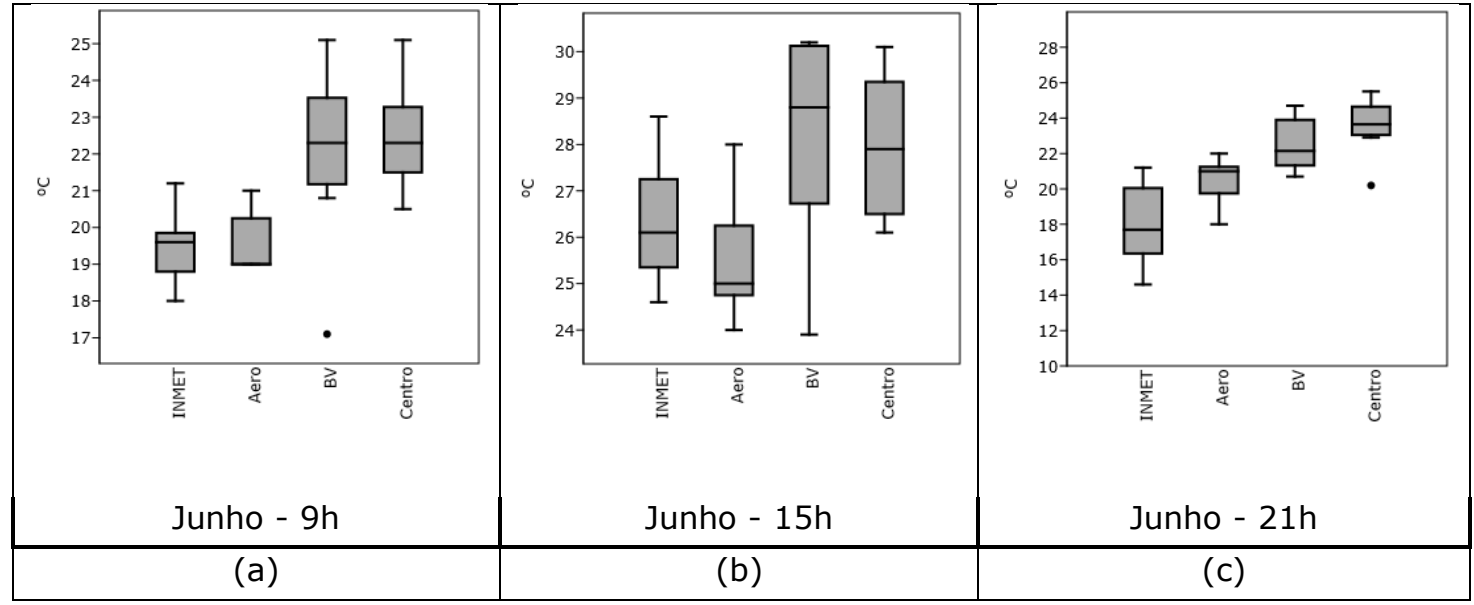

Figura 6 - Gráficos box plot para as temperaturas no mês de Junho

Situação similar pode ser observada nos dados do mês de julho (Figura 8). O gráfico das 9h (Figura 8a) mostra a forte amplitude nos dados do Boa Vista e Centro. No entanto, os resultados da estatística aplicada (ANOVA e Teste Tukey) consideraram que apenas os dados do Centro variaram significativamente em relação aos demais sítios.

Nos dados das 15h (Figura 8b), embora a amplitude, também, tenha sido uma característica marcante, a estatística aplicada não considerou significativa a variância os dados.

Por fim, nos dados das 21h (Figura 8c), novamente os dados do Centro demonstraram significância estatística em relação aos dados dos demais sítios (Tabela 3). Provavelmente, efeito da energia acumulada ao longo do dia, sendo transferida para 0 ar sob a forma de irradiação noturna, mantendo as temperaturas mais elevadas que as dos demais sítios.

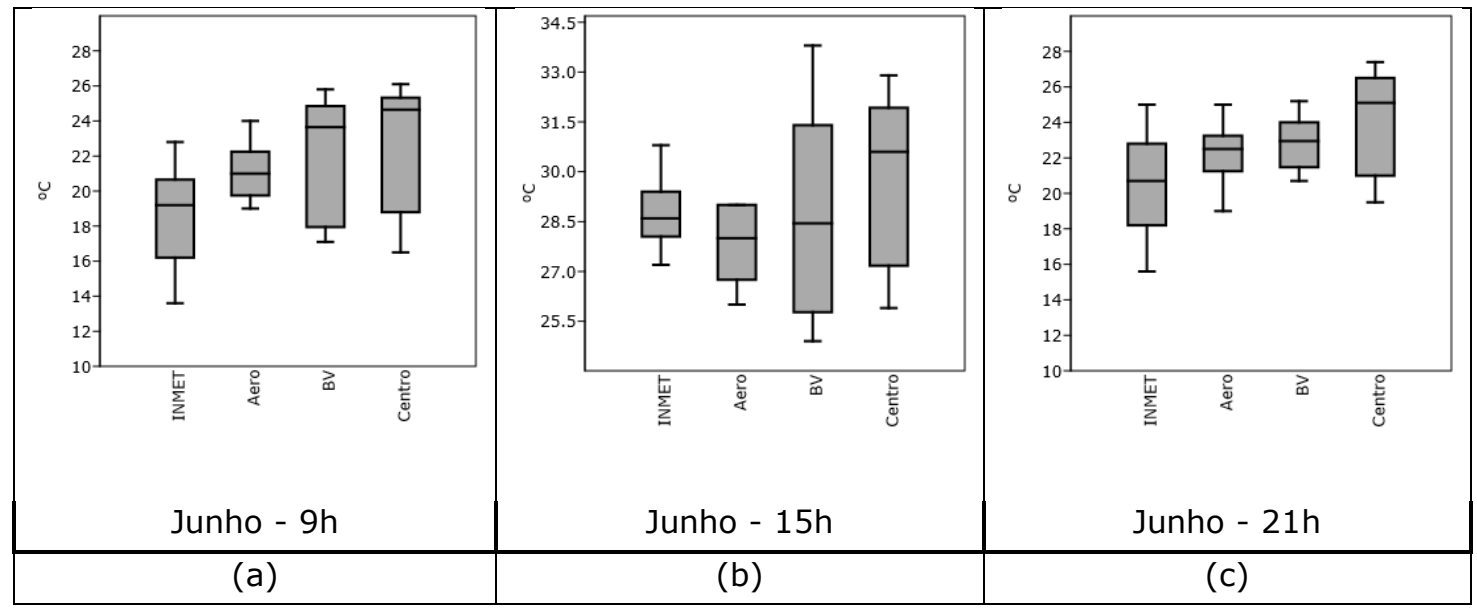

Figura 7 - Gráficos box plot para as temperaturas no mês de Julho 
Novamente, os gráficos dos dados de agosto (Figuras 9a, 9b e 9c) demonstram a forte amplitude térmica peculiar à estação do inverno, aliada a outra característica marcante: a concentração dos dados no $3^{\circ}$ quartil das séries.

A aplicação da estatística ANOVA e Teste de Tukey não considerou significativa as variâncias entre os sítios nos dados das $9 \mathrm{~h}$ e das $15 \mathrm{~h}$. No entanto, considerando os dados das $21 \mathrm{~h}$, os dados do Centro variaram significativamente em relação aos dados do INMET. Tal resultado corrobora com a ideia das condições do espaço urbano contribuir para que as temperaturas superficiais sejam superiores, sobretudo, em relação aos espaços não urbanos.

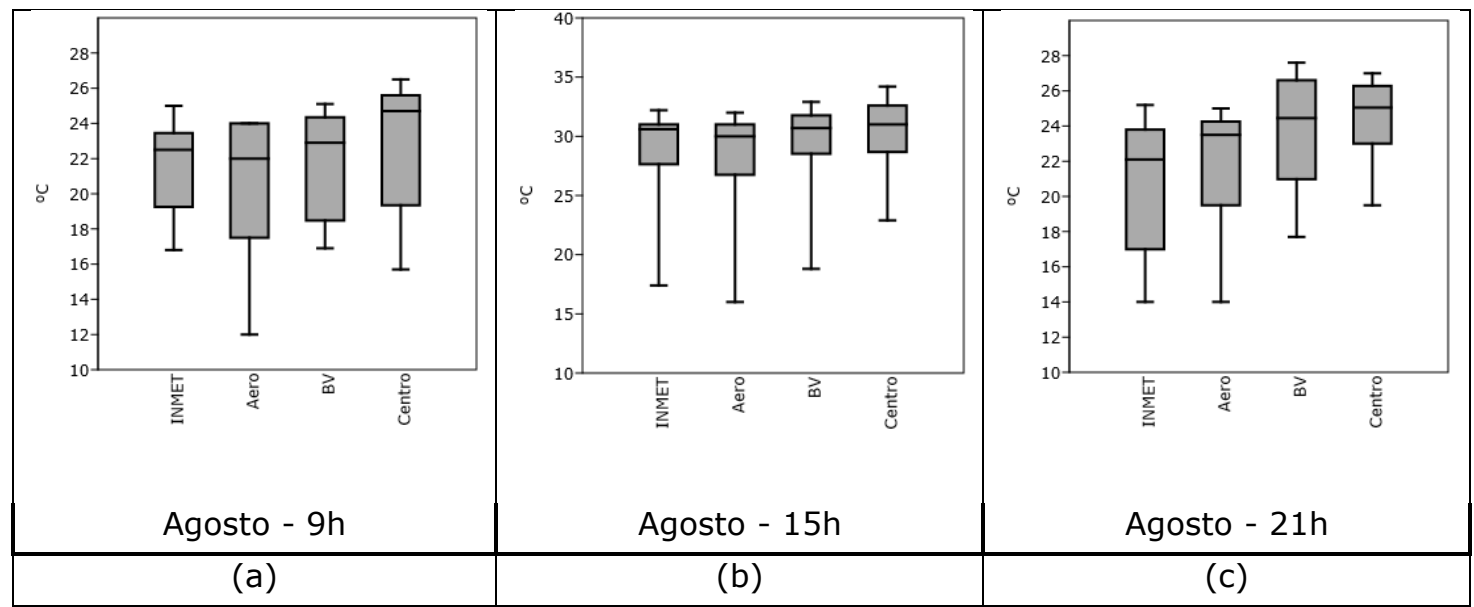

Figura 8 - Gráficos box plot para as temperaturas no mês de Agosto

Os dados de setembro (Figura 10) sugerem resultados igualmente interessantes. Nos três horários observa-se que as temperaturas do Boa Vista, e principalmente, do Centro destacam-se em relação aos sítios Aeroporto e INMET.

Nos três horários, verifica-se que a amplitude térmica é menor nos sítios Boa Vista e Centro, e maior nos sítios Aeroporto e INMET, bem como suas respectivas medianas.

Os resultados dos testes estatísticos (Tabelas 2 e 3) demonstraram que, para as $9 \mathrm{~h}$, os dados do Centro variaram significativamente em relação aos dados do INMET.

No horário das $15 \mathrm{~h}$, além da mesma relação observada para o horário das 9h, os dados do Centro e do Boa Vista variaram em relação aos dados do Aeroporto.

Por fim, para as $21 \mathrm{~h}$, Centro e Boa Vista variaram em relação ao Aeroporto.

A partir do final de setembro, com o início da primavera, pouco à pouco, os dias voltam a ficar mais longos (aumento do fotoperíodo) e com isso, as superfícies ficam mais tempo expostas à radiação solar.

Tais condições são responsáveis pelo maior aquecimento dos espaços mais densamente urbanizados em relação aos menos urbanizados. Acrescente a 
esse fator, a baixa umidade do ar típica da estação seca, a qual contribui para que os materiais constituintes do espaço urbano aumentem sua capacidade de irradiação, elevando as temperaturas nesses locais.

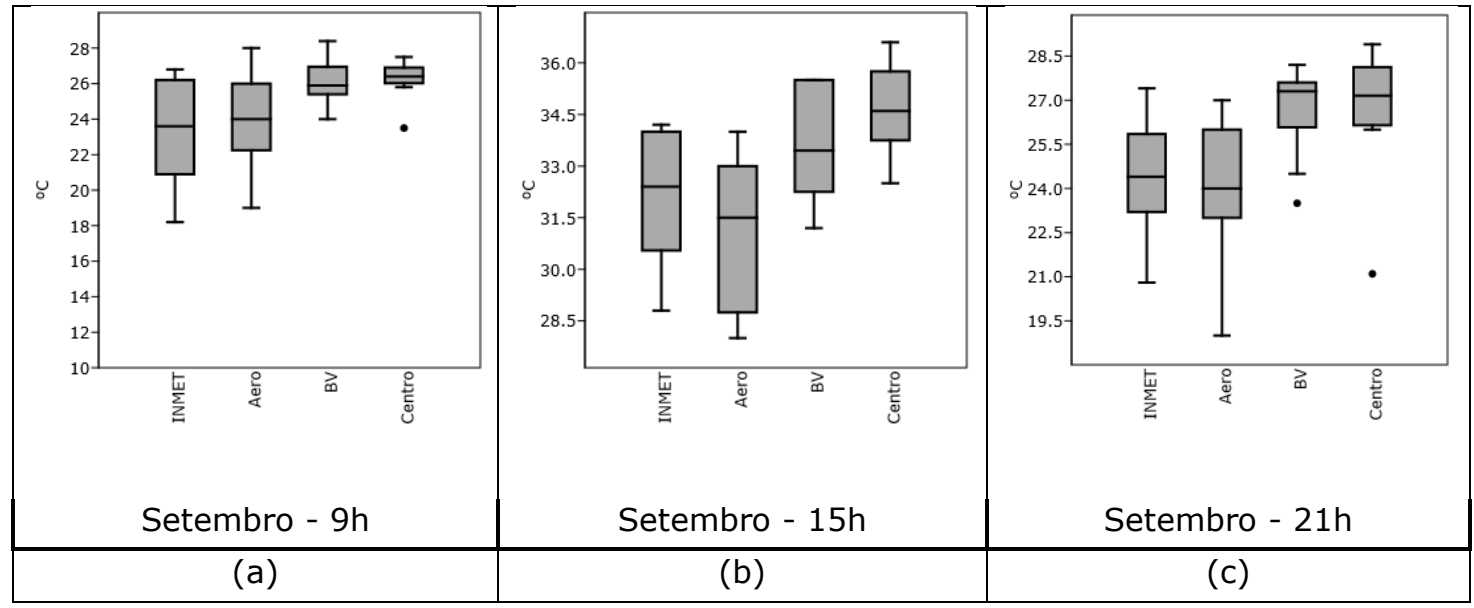

Figura 9 - Gráficos box plot para as temperaturas no mês de Setembro

A análise dos dados do mês de outubro (Figura 11) demonstra que no primeiro horário de coleta $(9 \mathrm{~h})$ as medianas dos quatro sítios estão bem próximas. A distribuição dos dados do INMET e do Aeroporto parece ter sido maior do que a distribuição dos dados do Boa Vista e do Centro. Os gráficos das temperaturas dos sítios Boa Vista e Centro, demonstram a concentração de dados entre o $3^{\circ}$ quartil e o valor máximo.

A estatística aplicada (Tabelas 2 e 3) demonstra que a variância dos dados das $9 \mathrm{~h}$ não foi considerada significativa. Já, as estatísticas das $15 \mathrm{~h}$ e das $21 \mathrm{~h}$ demonstram que a variância entre os sítios foi significativa.

Para as $15 \mathrm{~h}$, os dados do Centro variaram significativamente em relação aos dados do INMET e Aeroporto, bem como os dados do Boa Vista, também, variaram em relação ao Aeroporto (Figura 11b).

Comportamento similar pode ser observado nos dados das $21 \mathrm{~h}$ onde os dados do Boa Vista e do Centro variaram em relação aos dados do Aeroporto.

As temperaturas mais elevadas nos sítios mais urbanizados (centro e bairro) refletem o papel dos materiais construídos acumulando mais energia recebida ao longo do dia e, assim, irradiando energia por mais tempo durante a noite.

Alia-se a esse comportamento o fato do mês de outubro estar apresentando tendência de redução em seus totais pluviométricos e da umidade relativa nos últimos 59 anos, prolongando a estação seca na região de Uberaba (SANCHES et al., 2017). 


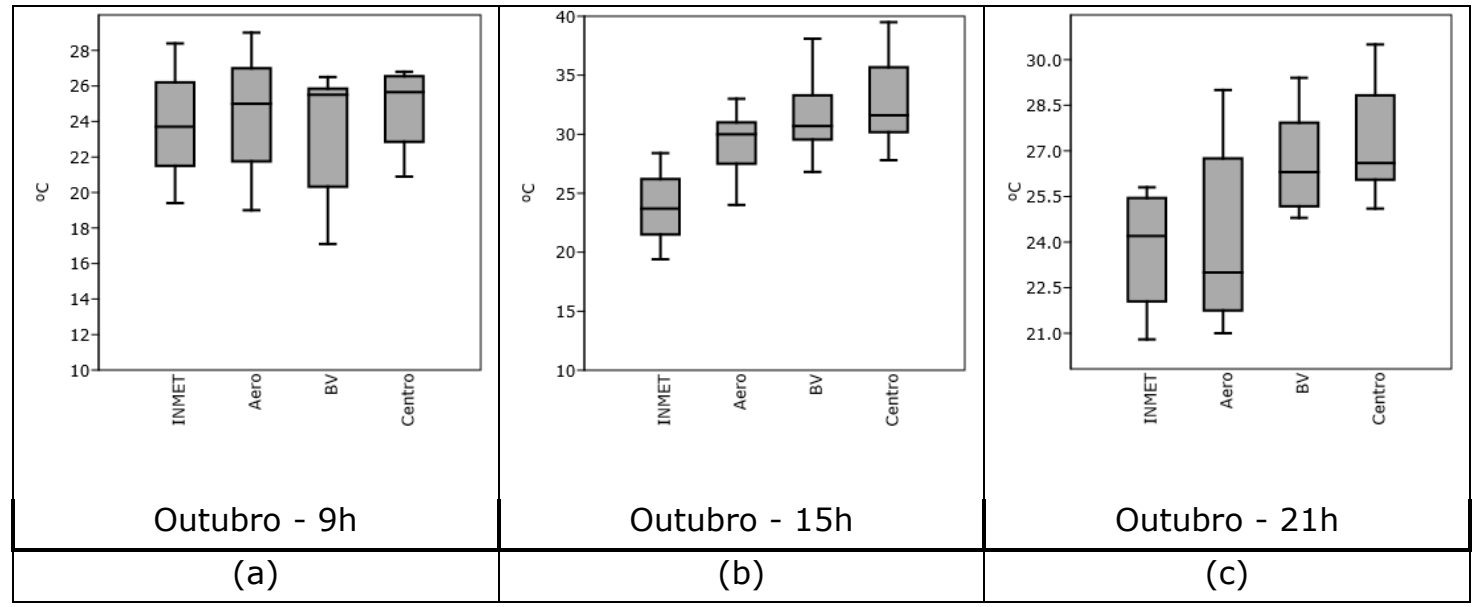

Figura 10 - Gráficos box plot para as temperaturas no mês de Outubro

Os dados de Novembro, para as 9h (Figura 12a) demonstram diferente distribuições quando comparados os sítios. No entanto, a estatística ANOVA e Teste de Tukey (Tabelas 2 e 3) considerou que não houve variação significativa entre os dados neste horário.

Entretanto, analisando os dados das $15 \mathrm{~h}$ e das $21 \mathrm{~h}$ (Figuras $12 \mathrm{~b}$ e $12 \mathrm{c}$ ) e suas estatísticas, verifica-se que os dados do Centro variaram em relação aos dados do Aeroporto (15h) e os dados do Boa Vista e Centro variaram, significativamente, em relação aos dados do INMET e do Aeroporto no horário noturno.

Novamente, atribuem-se essas diferenças significativas aos tipos de materiais construtivos do espaço urbano (asfalto, concreto, telhados etc.) aliados a reduzidas áreas verdes.

Nessa época do ano, os dias ficam mais longos o que favorecem a maior incidência de radiação solar sobre a superfície.

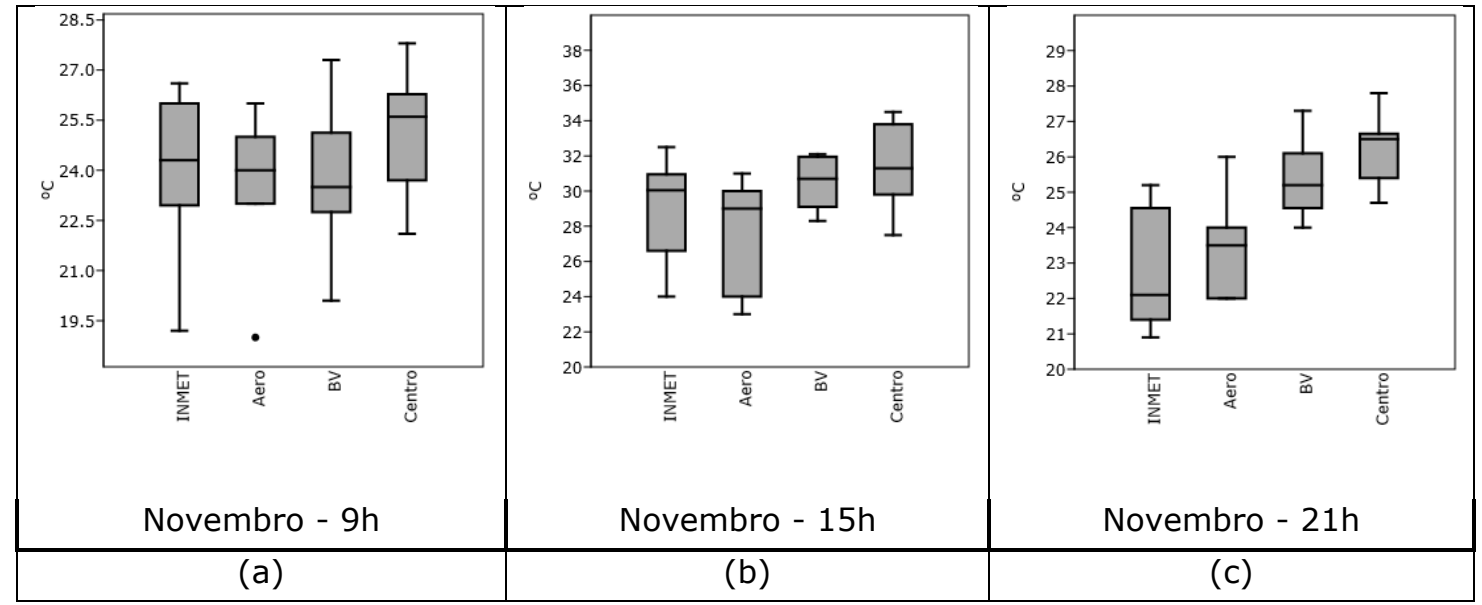

Figura 11 - Gráficos box plot para as temperaturas no mês de Novembro 
Por fim, os gráficos da Figura 13 demonstram a comparação dos sítios analisados para o mês de dezembro. Novamente, para a temperatura das $9 \mathrm{~h}$ (Figura 13a e Tabelas 2 e 3) a estatística aplicada não indicou variações significativas entre os dados dos sítios. Já para os dados das $15 \mathrm{~h}$, os testes apontaram que os dados do Centro variaram em relação aos dados do Aeroporto (Tabelas 2 e 3).

No gráfico de temperatura das $21 \mathrm{~h}$ (Figura 13c) observa-se, por meio dos dados (Tabelas 2 e 3), a ação dos materiais constituintes do espaço urbano central e do bairro Boa Vista promovendo temperaturas significativamente mais elevadas que as observadas nos sítios do Aeroporto e do INMET. Os gráficos representam, claramente, a ação da energia noturna irradiada promovendo temperaturas mais elevadas.

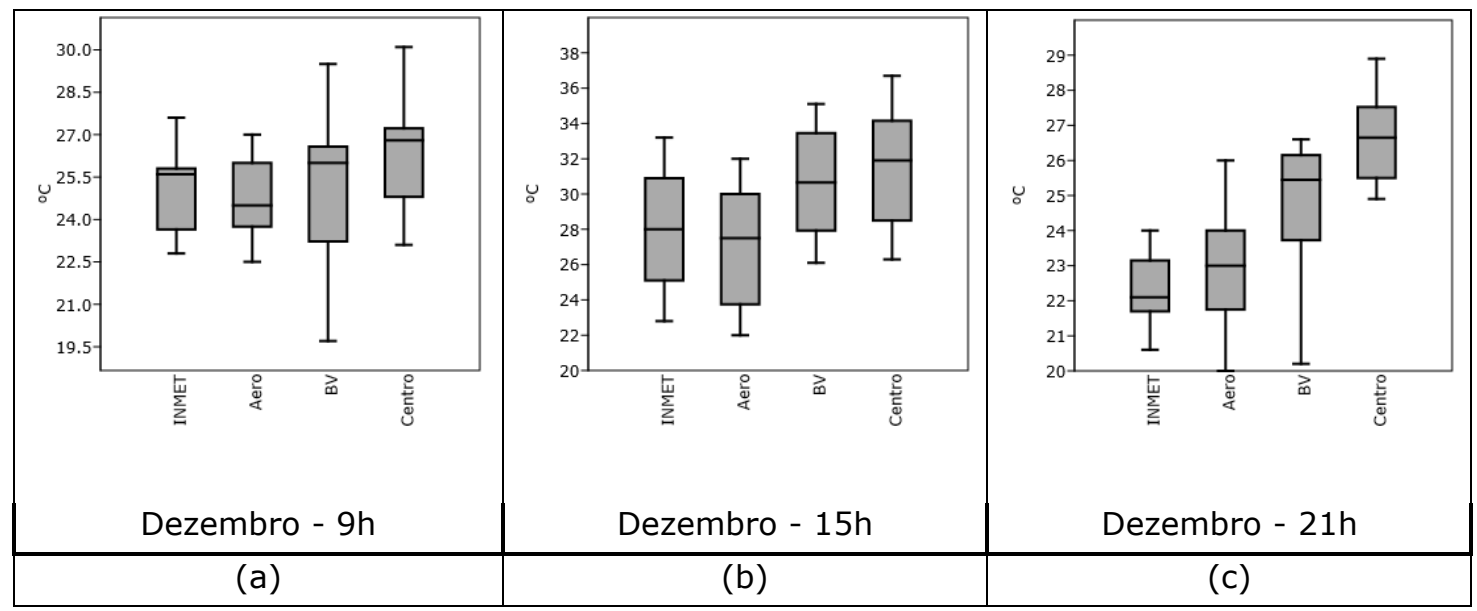

Figura 12 - Gráficos box plot para as temperaturas no mês de Dezembr 
Tabela 2 - Resultado do valor de F (teste de Fischer) para ANOVA para os meses de janeiro a dezembro de 2016.

\begin{tabular}{|c|c|c|c|c|c|c|c|c|c|c|c|c|c|}
\hline \multirow{5}{*}{$\begin{array}{c}9 \mathrm{~h} \\
15 \mathrm{~h} \\
21 \mathrm{~h} \\
\end{array}$} & \multicolumn{3}{|c|}{ Janeiro } & \multicolumn{2}{|l|}{ Fevereiro } & \multicolumn{2}{|l|}{ Março } & \multicolumn{2}{|l|}{ Abril } & \multicolumn{2}{|l|}{ Maio } & \multicolumn{2}{|l|}{ Junho } \\
\hline & F-crítico & p-valor & $F$ & p-valor & $\boldsymbol{F}$ & p-valor & $F$ & p-valor & $F$ & p-valor & $\boldsymbol{F}$ & p-valor & $\boldsymbol{F}$ \\
\hline & 2,86 & $1,48 \mathrm{E}-03$ & 6,32 & $4,57 \mathrm{E}-06$ & 13,52 & 0,006 & 4,82 & 0,582 & 0,65 & 0,146 & 1,90 & $1,1 \mathrm{E}-05$ & 12,28 \\
\hline & 2,86 & 0,025 & 3,47 & 0,256 & 1,4 & 0,030 & 3,24 & 0,386 & 1,03 & 0,348 & 1,13 & $6,60 \mathrm{E}-04$ & 7,20 \\
\hline & 2,86 & $3,00 \mathrm{E}-09$ & 25,99 & $1,36 \mathrm{E}-06$ & 15,34 & $1,04 \mathrm{E}-04$ & 9,35 & 0,087 & 2,36 & 0,075 & 2,49 & $1,09 \mathrm{E}-08$ & 23,90 \\
\hline & & \multicolumn{2}{|c|}{ Julho } & Agosto & & \multicolumn{2}{|l|}{ Setembro } & \multicolumn{2}{|l|}{ Outubro } & \multicolumn{2}{|c|}{ Novembro } & \multicolumn{2}{|l|}{ Dezembro } \\
\hline & F-crítico & $p$-valor & $\boldsymbol{F}$ & $p$-valor & $\boldsymbol{F}$ & $p$-valor & $F$ & p-valor & $F$ & $p$-valor & $F$ & $p$-valor & $\boldsymbol{F}$ \\
\hline 9h & 2,86 & $2,28 \mathrm{E}-02$ & 3,59 & 0,685 & 0,49 & $8,63 \mathrm{E}-03$ & 4,52 & 0,753 & 0,40 & 0,363 & 1,09 & 0,270 & 1,36 \\
\hline $15 \mathrm{~h}$ & 2,86 & 0,169 & 1,77 & 0,732 & 0,43 & $3,29 \mathrm{E}-04$ & 7,98 & $6,21 \mathrm{E}-07$ & 16,58 & 0,009 & 4,38 & 0,016 & 3,90 \\
\hline $21 \mathrm{~h}$ & 2,86 & $8,12 \mathrm{E}-03$ & 4,57 & 0,093 & 2,30 & $4,60 \mathrm{E}-03$ & 5,14 & $9,42 \mathrm{E}-04$ & 6,80 & $5,24 \mathrm{E}-07$ & 16,86 & $4,34 \mathrm{E}-07$ & 17,17 \\
\hline
\end{tabular}

Tabela 3 - Resultados dos p-valores do Teste de Tukey para os meses de janeiro a dezembro de 2016.

\begin{tabular}{|c|c|c|c|c|c|c|c|c|c|c|c|c|c|c|c|c|c|c|c|c|c|c|c|c|}
\hline & \multicolumn{2}{|c|}{ Janeiro - 9h } & & & \multicolumn{4}{|c|}{ Fevereiro - 9h } & \multicolumn{4}{|c|}{ Março-9h } & \multicolumn{4}{|c|}{ Abril -9h } & \multicolumn{4}{|c|}{ Maio - 9h } & \multicolumn{4}{|c|}{ Junho-9h } \\
\hline & INMET & Aero & $B V$ & Centro & INMET & Aero & $B V$ & Centro & INMET & Aero & $B V$ & Centro & INMET & Aero & $B V$ & Centro & INMET & Aero & $B V$ & Centro & INMET & Aero & $B V$ & \multirow{4}{*}{$\begin{array}{l}\text { Centro } \\
\mathbf{2 , 6 2 \mathrm { E } -} \\
\mathbf{0 4} \\
\mathbf{5 , 0 2 \mathrm { E } -} \\
\mathbf{0 4} \\
0,962\end{array}$} \\
\hline INMET & & 0,926 & 0,903 & 0,008 & & 0,951 & 0,063 & $\begin{array}{l}1,64 E- \\
04\end{array}$ & & 0,992 & 0,996 & 0,012 & & 1,000 & 0,972 & 0,603 & & 0,997 & 0,984 & 0,167 & & 0,996 & 0,001 & \\
\hline Aero & 0,873 & & 0,569 & 0,002 & 0,751 & & 0,185 & 2,00E- & 0,404 & & 1 & 0,025 & 0,081 & & 0,981 & 0,638 & 0,288 & & 0,999 & 0,241 & 0,310 & & 0,002 & \\
\hline \multirow{3}{*}{ centro } & $\begin{array}{l}0,966 \\
4,831\end{array}$ & $\begin{array}{l}1,839 \\
5,703\end{array}$ & 3,864 & 0,046 & $\begin{array}{l}3,667 \\
8,114\end{array}$ & $\begin{array}{l}2,916 \\
7,363\end{array}$ & 4,447 & $\begin{array}{l}04 \\
0,017\end{array}$ & $\begin{array}{l}0,308 \\
4,619\end{array}$ & $\begin{array}{l}0,096 \\
4,215\end{array}$ & 4,311 & 0,021 & $\begin{array}{l}0,617 \\
1,761\end{array}$ & $\begin{array}{l}0,535 \\
1,680\end{array}$ & 1,145 & 0,850 & $\begin{array}{l}0,510 \\
2,994\end{array}$ & $\begin{array}{l}0,222 \\
2,705\end{array}$ & 2,484 & 0,311 & $\begin{array}{l}5,860 \\
6,545\end{array}$ & $\begin{array}{l}5,550 \\
6,236\end{array}$ & 0,686 & \\
\hline & \multicolumn{2}{|c|}{ J, } & & & \multicolumn{4}{|c|}{ Fevereiro - 15h } & \multicolumn{4}{|c|}{ Março - 15h } & \multicolumn{4}{|c|}{$\frac{1,101}{\text { Abril - 15h }}$} & \multicolumn{4}{|c|}{ Maio - 15h } & \multicolumn{4}{|c|}{ Junho - 15h } \\
\hline & INMET & Aero & $B V$ & Centro & INMET & Aero & $B V$ & Centro & INMET & Aero & $B V$ & Centro & INMET & Aero & $B V$ & Centro & INMET & Aero & $B V$ & Centro & INMET & Aero & $B V$ & Centro \\
\hline INMET & & 0,438 & 0,993 & 0,338 & & 0,976 & 0,744 & 0,233 & & 0,682 & 1 & 0,224 & & 0,931 & 0,999 & 0,669 & & 0,992 & 0,955 & 0,488 & & 0,579 & 0,058 & 0,095 \\
\hline & 2,147 & & 0,296 & 0,014 & 0,586 & & 0,932 & 0,438 & 1,578 & & 0,645 & 0,020 & 0,849 & & 0,878 & 0,319 & 0,397 & & 0,855 & 0,332 & 1,816 & & 0,002 & 0,004 \\
\hline \multirow[t]{3}{*}{ Centro } & $\begin{array}{l}0,381 \\
2,406\end{array}$ & $\begin{array}{l}2,527 \\
4,552\end{array}$ & 2,025 & 0,488 & $\begin{array}{l}1,431 \\
2,732\end{array}$ & $\begin{array}{l}0,846 \\
2,147\end{array}$ & 1,301 & 0,794 & $\begin{array}{l}0,087 \\
2,765\end{array}$ & $\begin{array}{l}1,666 \\
4,344\end{array}$ & 2,678 & 0,249 & $\begin{array}{l}0,205 \\
1,609\end{array}$ & $\begin{array}{l}1,055 \\
2,458\end{array}$ & 1,404 & 0,755 & $\begin{array}{l}0,731 \\
2,025\end{array}$ & $\begin{array}{l}1,128 \\
2,423\end{array}$ & 1,295 & 0,797 & $\begin{array}{l}3,711 \\
3,395\end{array}$ & $\begin{array}{l}5,527 \\
5,212\end{array}$ & 0,316 & \\
\hline & \multicolumn{2}{|c|}{ Janeiro - 21h } & & & \multicolumn{4}{|c|}{ Fevereiro - 21 h } & \multicolumn{4}{|c|}{ Março - 21 h } & \multicolumn{4}{|c|}{ Abril - 21h } & \multicolumn{4}{|c|}{ Maio - 21h } & \multicolumn{4}{|c|}{ Junho - 21h } \\
\hline & INMET & Aero & $\overline{B V}$ & Centro & INMET & Aero & $\overline{B V}$ & Centro & INMET & Aero & $\overline{B V}$ & Centro & INMET & Aero & $\overline{B V}$ & Centro & INMET & Aero & $\overline{B V}$ & Centro & INMET & Aero & $B V$ & Centro \\
\hline INMET & & 0,935 & $1,59 \mathrm{E}-$ & $1,59 \mathrm{E}-$ & & 0,002 & 0,138 & 0,526 & & 0,844 & 0,008 & $4,27 E_{-}$ & & 0,732 & 0,122 & 0,135 & & 0,776 & 0,233 & 0,070 & & 0,003 & $1,59 E^{-}$ & $1,20 E-$ \\
\hline Aero & 0,834 & & $\begin{array}{l}\mathbf{l} \\
\begin{array}{l}1,61 \\
04\end{array}\end{array}$ & $\begin{array}{l}04 \\
1,61 E- \\
04\end{array}$ & 5,707 & & 1,59E- & $1,83 \mathrm{E}-$ & 1,162 & & 0,060 & $\begin{array}{l}04 \\
0,003\end{array}$ & 1,459 & & 0,602 & 0,634 & 1,349 & & 0,763 & 0,397 & 5,315 & & $\begin{array}{l}06 \\
0,069\end{array}$ & $\begin{array}{l}{ }_{9,928}^{08}- \\
0.92\end{array}$ \\
\hline B.Vista & 9,229 & 8,395 & & $\begin{array}{l}0_{1}^{4} \\
1\end{array}$ & 3,134 & 8,840 & & $\begin{array}{l}04 \\
0,832\end{array}$ & 4,861 & 3,700 & & 0,654 & 3,221 & 1,762 & & 1 & & 1,383 & & 0,928 & 8,917 & 3,602 & & 0,376 \\
\hline Centro & 9,229 & 8,395 & 0 & & 1,936 & 7,643 & 1,197 & & 6,506 & 5,344 & 1,644 & & 3,149 & 1,690 & 0,072 & & 3,598 & 2,249 & 0,866 & & 11,220 & 5,906 & 2,303 & \\
\hline & $\begin{array}{l}\text { Julno - } \\
\text { INMET }\end{array}$ & hero & $\overline{B V}$ & Centro & $\begin{array}{l}\text { Agosto } \\
\text { INMET }\end{array}$ & $\frac{9 \mathrm{~h}}{\text { Aero }}$ & $\overline{B V}$ & Centro & Setemb & $\frac{-9 \mathrm{~h}}{\mathrm{D}}$ & $\overline{B V}$ & Centro & $\frac{\text { Outubr }}{I I M E T}$ & $\frac{-9 \mathrm{~h}}{\text { - }}$ & $\overline{B V}$ & Centro & $\frac{\text { Noveml }}{\text { INMET }}$ & $\frac{0-9 h}{\text { ofero }}$ & $\overline{B V}$ & Centro & $\frac{\text { Dezemb }}{\text { INMET }}$ & $\frac{o-9 h}{\text { o-9ho }}$ & BV & Centro \\
\hline INMET & & 0,235 & $\frac{B V}{0,087}$ & 0,018 & & 0,927 & & $\begin{array}{l}\text { Centro } \\
0,929\end{array}$ & & $\begin{array}{l}\text { Aero } \\
0,937\end{array}$ & $\frac{B V}{0,041}$ & 0,028 & & $\begin{array}{l}\text { Aero } \\
0,949\end{array}$ & & 0,828 & & $\begin{array}{l}\text { Aero } \\
0,977\end{array}$ & $\frac{B V}{0,979}$ & $\begin{array}{l}\text { Centro } \\
0,653\end{array}$ & & $\begin{array}{l}\text { Aero } \\
0,987\end{array}$ & $\frac{B V}{0,999}$ & $\begin{array}{l}\text { Centro } \\
0,427\end{array}$ \\
\hline Aero & 2,726 & & 0,955 & 0,636 & 0,869 & & 0,942 & 0,617 & 0,823 & & 0,143 & 0,104 & 0,763 & & 0,924 & 0,989 & 0,575 & & & 0,408 & 0,478 & & 0,961 & 0,257 \\
\hline B.Vista & 3,454 & 0,728 & & 0,905 & 0,072 & 0,796 & & 0,912 & 3,931 & 3,108 & & 0,999 & 0,120 & 0,882 & & 0,784 & 0,559 & 0,016 & & 0,414 & 0,216 & 0,693 & & 0,517 \\
\hline Centro & 4,412 & $\frac{1,686}{5}$ & 0,957 & & 0,860 & 1,728 & 0,932 & & 4,158 & 3,335 & 0,227 & & 1,209 & 0,447 & 1,329 & & 1,646 & 2,222 & 2,206 & & $\frac{2,173}{19}$ & 2,650 & 1,957 & \\
\hline & Julho - & & & & Agosto & $15 \mathrm{~h}$ & & & Setemb & $-15 h$ & & & Outubr & $-15 \mathrm{~h}$ & & & Noveml & $0-15 h$ & & & $\begin{array}{l}\text { Dezemb } \\
\end{array}$ & $0-15 h$ & & \\
\hline & INMET & Aero & $B V$ & Centro & INMET & Aero & $B V$ & Centro & INMET & Aero & $B V$ & Centro & INMET & Aero & $B V$ & Centro & INMET & Aero & $B V$ & Centro & INMET & Aero & $B V$ & Centro \\
\hline INMET & & 0,694 & 1 & 0,625 & & 0,993 & 0,982 & 0,854 & & 0,576 & 0,274 & 0,013 & & 0,002 & $1,26 \mathrm{E}-$ & $8,89 \mathrm{E}-$ & & 0,691 & 0,473 & 0,140 & & 0,925 & 0,352 & 0,103 \\
\hline Aero & 1,550 & & 0,707 & 0,116 & 0,377 & & 0,919 & 0,711 & 1,823 & & 0,018 & $3,43 \mathrm{E}-$ & 5,679 & & $\begin{array}{l}05 \\
0,384 \\
0.54\end{array}$ & $\begin{array}{l}\mathbf{0 7} \\
0,080\end{array}$ & 1,556 & & 0,068 & 0,011 & 0,878 & & 0,118 & 0,025 \\
\hline B.Vista & 0,029 & 1,521 & & 0,612 & 0,526 & 0,903 & & 0,973 & 2,595 & $\begin{array}{l}4,418 \\
6417\end{array}$ & & $\begin{array}{l}{ }^{04} \\
0,500\end{array}$ & 7,960 & 2,282 & 1227 & 0,821 & 2,062 & 3,619 & 105 & 0,875 & 2,369 & 3,246 & & 0,901 \\
\hline Centro & $\frac{1,711}{116}$ & $\begin{array}{r}3,261 \\
1 h\end{array}$ & 1,740 & & $\frac{1,132}{\text { Agosto }}$ & $\frac{1,510}{21 \mathrm{~h}}$ & 0,607 & & $\frac{4,594}{\text { Setemb }}$ & $\frac{6,417}{1-21 \mathrm{~h}}$ & 1,999 & & $\frac{9,187}{\text { Outubr }}$ & $\frac{3,509}{-21 \mathrm{~h}}$ & 1,227 & & $\frac{3,126}{\text { Novemt }}$ & $\frac{4,682}{0-21 \mathrm{~h}}$ & 1,064 & & & 4,218 & 0,972 & \\
\hline & $\begin{array}{l}\text { Julino- } \\
\text { INMET }\end{array}$ & $\frac{1 \mathrm{~h}}{\text { Aero }}$ & $\overline{B V}$ & Centro & $\begin{array}{l}\text { Agosto } \\
\text { INMET }\end{array}$ & $\frac{2 \mathrm{hih}}{\text { Aero }}$ & $B V$ & Centro & $\begin{array}{l}\text { Setemb } \\
\text { INMET }\end{array}$ & $\frac{-21 \mathrm{~h}}{\text { Aero }}$ & $\overline{B V}$ & Centro & $\begin{array}{l}\text { Outubr } \\
\text { INMEET }\end{array}$ & $\frac{-21 \mathrm{~h}}{\text { Aero }}$ & $\overline{B V}$ & Centro & $\frac{\text { Noveml }}{\text { INMET }}$ & $\frac{\text { o-21h }}{\text { Aero }}$ & $B V$ & Centro & $\frac{\text { Dezemb }}{\text { INMET }}$ & $\frac{0-21 \mathrm{~h}}{\text { oero }}$ & $B V$ & Centro \\
\hline INMET & & 0,341 & 0,117 & 0,004 & & 0,907 & 0,264 & 0,107 & & 0,971 & 0,065 & 0,077 & & 0,994 & $\begin{array}{l}2,76 E- \\
02\end{array}$ & $\begin{array}{l}4,79 \mathrm{E}- \\
03\end{array}$ & & 0,8182 & $\begin{array}{l}4,33 \mathrm{E}- \\
04\end{array}$ & $\begin{array}{l}2,82 \mathrm{E}- \\
06\end{array}$ & & 0,893 & 0,004 & $\begin{array}{l}1,24 E- \\
06\end{array}$ \\
\hline Aero & 2,396 & & 0,929 & 0,224 & 0,952 & & 0,641 & 0,354 & 0,626 & & 0,023 & 0,028 & 0,357 & & $\begin{array}{l}0,050 \\
0,05\end{array}$ & $\begin{array}{l}0,009 \\
03\end{array}$ & 1,236 & & $\begin{array}{l}0,005 \\
0,005\end{array}$ & 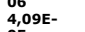 & 1,004 & & 0,028 & 1,09E- \\
\hline B.Vis & 3,254 & 0,858 & & 0,540 & 2,626 & 1,675 & & 0,962 & 3,646 & 4,272 & & 1 & 4,165 & 3,808 & & 0,907 & 6,306 & 5,070 & & $\begin{array}{l}\begin{array}{l}05 \\
0,3599\end{array} \\
0,10\end{array}$ & 5,165 & 4,161 & & 0,045 \\
\hline Centro & 5,160 & 2,764 & 1,906 & & 3,314 & 2,362 & 0,687 & & 3,537 & 4,163 & 0,110 & & 5,117 & 4,760 & 0,952 & & 8,652 & 7,416 & 2,346 & & 9,034 & 8,030 & 3,869 & \\
\hline
\end{tabular}




\subsection{USO E OCUPAÇÃO DA SUPERFÍCIE}

Por fim, a última etapa do trabalho consistiu na caracterização do uso e ocupação do entorno de cada sítio de coleta de dados utilizando o software QGIS. Dessa forma, a Figura 13 mostra tal caracterização a partir de um raio de 100 metros do ponto de coleta $\left(31.400 \mathrm{~m}^{2}\right)$, cf. sugerem Hasenack (1989) e Oke (2016).

Verifica-se a presença de cobertura vegetal rasteira, mata ciliar e corpo d'água no raio de $100 \mathrm{~m}$ do entorno do INMET (Figura 13a); casas, edifícios e praças no entorno do bairro Boa Vista (Figura 13b); no Centro predominam prédios, casas, comércio, revestimento asfáltico e alguma arborização em logradouros ou quintais residenciais (Figura 13c); no raio do entorno ao Aeroporto, predomina o revestimento asfáltico, concreto e canteiros gramados. Esses elementos contribuem para a variabilidade térmicas observadas.
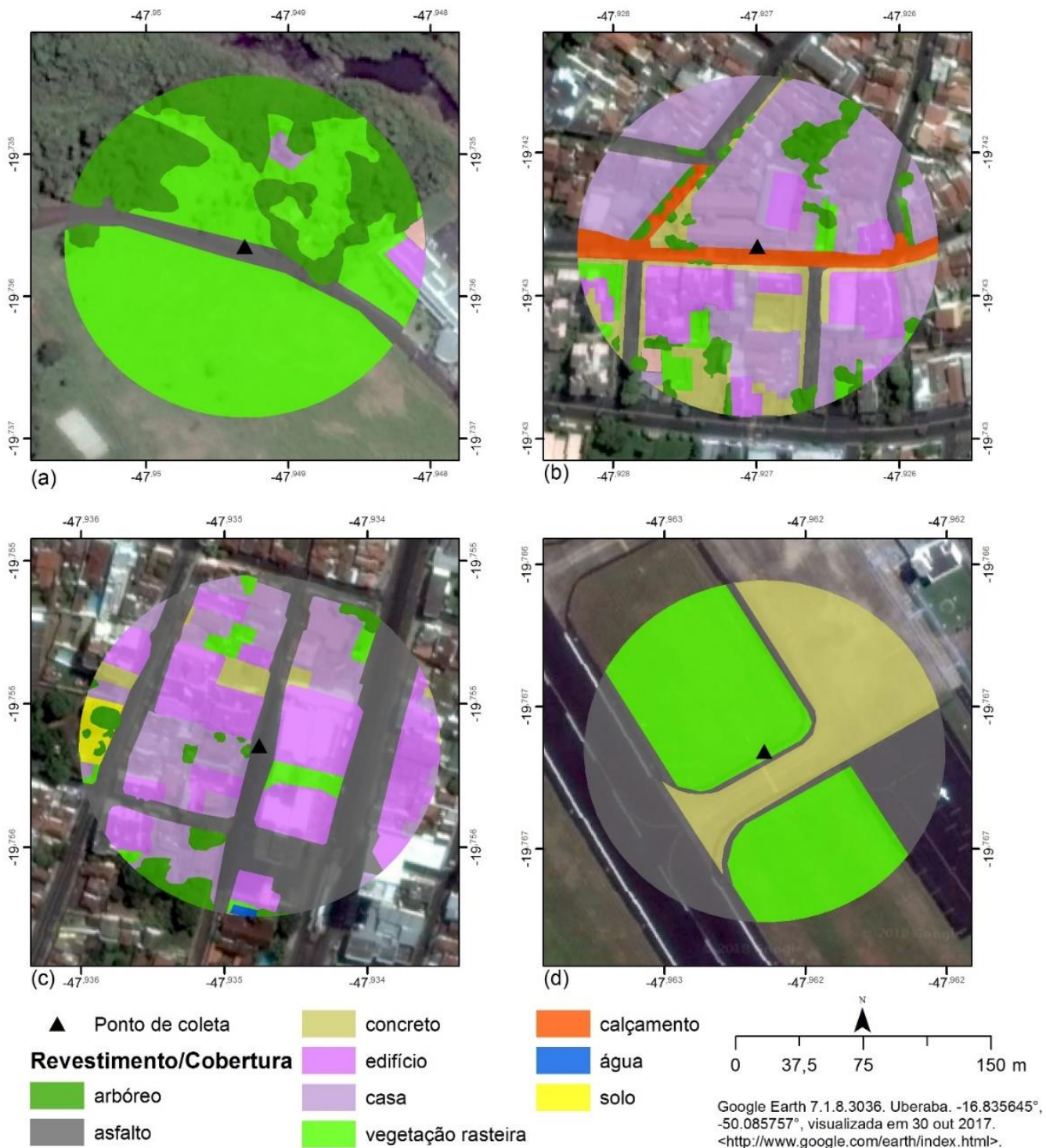

Figura 13 - Caracterização do uso e ocupação no entorno (100 metros) do sítio INMET (a), sítio Boa Vista (bairro) (b), sítio Centro (c) e sítio Aeroporto (d). 
Tabela 4 - Área e percentual de uso e ocupação no entorno dos pontos de coleta de dados.

\begin{tabular}{|c|c|c|c|c|c|c|c|c|}
\hline \multirow{2}{*}{$\begin{array}{c}\text { Revestime } \\
\text { nto/Cober } \\
\text { tura }\end{array}$} & \multicolumn{2}{|c|}{ INMET } & \multicolumn{2}{|c|}{ Boa Vista } & \multicolumn{2}{|c|}{ Centro } & \multicolumn{2}{|c|}{ Aeroporto } \\
\hline & $\begin{array}{l}\text { Área } \\
\left(\mathrm{m}^{2}\right)\end{array}$ & $\begin{array}{c}\text { Percent. } \\
(\%)\end{array}$ & $\begin{array}{l}\text { Área } \\
\left(\mathrm{m}^{2}\right)\end{array}$ & $\begin{array}{c}\text { Percent. } \\
(\%)\end{array}$ & $\begin{array}{l}\text { Área } \\
\left(\mathrm{m}^{2}\right)\end{array}$ & $\begin{array}{c}\text { Percent. } \\
(\%)\end{array}$ & $\begin{array}{l}\text { Área } \\
\left(\mathrm{m}^{2}\right)\end{array}$ & $\begin{array}{c}\text { Percent. } \\
(\%)\end{array}$ \\
\hline Arbóreo & $8.630,6$ & 27,8 & $2.680,0$ & 8,4 & $1.422,0$ & 4,5 & 0 & $\begin{array}{ll}0 & 0\end{array}$ \\
\hline Asfalto & $1.990,2$ & 6,3 & $2.238,7$ & 7,4 & 10741,2 & 34,2 & $8.895,8$ & 28,3 \\
\hline Concreto & 0 & 0,0 & $3.147,4$ & 9,6 & 856,4 & 2,7 & $8.406,0$ & 26,8 \\
\hline Edifício & 362,9 & 1,2 & $4.654,7$ & 15,1 & 9803,5 & 31,2 & 0 & 0,0 \\
\hline Casa & 239,1 & 0,8 & $15.066,4$ & 47,5 & $6.902,9$ & 22,0 & 0 & 0,0 \\
\hline $\begin{array}{l}\text { Veg. } \\
\text { rasteira }\end{array}$ & $20.037,5$ & 63,6 & $1.234,2$ & 3,8 & $1.191,2$ & 3,8 & $14.098,4$ & 44,9 \\
\hline Calçamento & 0 & 0,0 & $2.055,5$ & 7,2 & 0 & 0,0 & 0 & 0,0 \\
\hline Água & 0,4 & 0,0 & 0 & 0,0 & 70,4 & 0,2 & 0 & 0,0 \\
\hline Solo & 138,8 & 0,4 & 323,0 & 1,0 & 412,7 & 1,3 & 0 & 0,0 \\
\hline Total & 31400,0 & 100 & 31400,0 & 100 & 31400,0 & 1003 & 1400,0 & 100 \\
\hline
\end{tabular}

A caracterização destes usos, com especial atenção para o entorno do sítio INMET, denota que a cobertura vegetal arbórea e arbustiva contribui para atenuar a temperatura do ar. Isso fica evidente quando comparado com os sítios do Centro e Bairro Boa Vista, que contém maior área construída em detrimento das condições naturais, resultando em temperaturas mais elevadas, como apontam os estudos de Tso et al (1990).

A análise do entorno sítio Aeroporto mostra que a maior proporção do uso e ocupação no raio de 100 metros corresponde a vegetação rasteira dos canteiros e arbustos no entorno do revestimento asfáltico (pista de pouso/decolagem) e o concreto (área de manobra das aeronaves). Outro aspecto importante no sítio Aeroporto é sua localização no topo de uma colina, portanto, sujeito a ação dos ventos e, devido às exigências legais (Área de Segurança Aeroportuária $\quad-\quad$ ASA) (http://www.mma.gov.br/port/conama/res/res95/res0495.html), com limitações no processo de verticalização no entorno.

Nos sítios Boa Vista (bairro) e Centro (UFTM) a reduzida proporção de áreas arborizadas (vegetação arbórea e vegetação rasteira) contribui para que ocorram valores mais elevados de temperatura uma vez que não há (ou há pouco) sombreamento de fachadas, calçadas e outros tipos de pavimentos por parte da vegetação.

Dessa forma, associa-se que os maiores valores observados nas temperaturas desses sítios, sejam decorrentes do tipo de uso e ocupação desses espaços urbanos, pois além de possuírem poucas áreas arborizadas, apresentam edificações com mais massa construída (concreto, cimento, asfalto e telhados), influenciando nas temperaturas mais elevadas conforme afirmam Tso et al (1990). 


\section{CONCLUSÕES}

O trabalho procurou analisar as temperaturas superficiais em quatro sítios representativos da cidade de Uberaba (MG) para os meses do ano de 2016.

A aplicação de técnicas estatísticas (ANOVA e Teste de Tukey) aos dados coletados demonstrou que a áreas mais densamente ocupadas (centro da cidade e bairro Boa Vista) apresentam temperaturas significativamente superiores às áreas de menor adensamento urbano (Estação Meteorológica do INMET e Aeroporto) na maior parte dos meses do ano.

A caracterização do uso e ocupação no entorno de cada sítio de coleta de dados por meio do processamento de imagem de satélite revelou que o adensamento urbano (e maior concentração de massa construída) na área central e no bairro Boa Vista influenciou (e influencia) nos valores mais elevados de temperatura em relação ao entorno da Estação Meteorológica do INMET e do Aeroporto.

Dessa forma, a partir das técnicas utilizadas (análises estatísticas aliadas a interpretação de imagem de satélite) é possível concluir que as maiores temperaturas registradas na região central da cidade de Uberaba caracterizam a formação do fenômeno da "ilha de calor urbana".

\section{REFERÊNCIAS}

ALVES, E.D.L. Ilha de calor urbana em cidade de pequeno porte e a influência de variáveis geourbanas. Revista Brasileira de Climatologia, Ano 13 -Vol. 20JAN/JUL 2017.

ALVES, L.M.; MARENGO, J.A.; CAMARGO JUNIOR, H. CASTRO, C. Início da estação chuvosa na região sudeste do Brasil: parte 1 - estudos observacionais. Revista Brasileira de Meteorologia, v.20, n.3.Dez., 2005.

AMORIM, M.C.C.T. Intensidade e forma da ilha de calor urbana em Presidente Prudente/SP: episódios de inverno. Geosul, Florianópolis, v. 20, n. 39, p 65-82, jan./jun. 2005.

AMORIM, M.C.C.T.; DUBREUIL, V.; CARDOSO, R.S. Modelagem espacial da Ilha de Calor Urbana em Presidente Prudente (SP) - Brasil. Revista Brasileira de Climatologia, Ano 11 - Vol. 16 - JAN/JUL 2015.

ANDRADE, A.R.; POTTKER, G.S.; OLIVEIRA FILHO, P.C.; MACHADO, A.L.F. Influence of land use on urban climate of a small town. Acta Scientiarum Technology. V.35. n.2. 2013. p.349-361.

ANDRADE, A.R.; ROSEGHINI, W.F.F.; MENDONÇA, F.A. Análise do campo térmico da cidade de Irati/PR: primeiros experimentos para a definição do clima urbano. Revista Brasileira de Climatologia, Ano 6 -Volume 6 -Junho/2010

ANJOS, M.W.B.; GANHO, N.; ARAÚJO, H.M. Uma análise dos contrastes topoclimáticos no espaço urbano e periurbano de Aracaju/SE: os campos térmicos e higrométricos. Revista Brasileira de Climatologia, Ano 9 - vol. 13 JUL/DEZ, 2013. 
BARROS, H.R.; LOMBARDO, M.A. A ilha de calor urbana e o uso e cobertura do solo em São Paulo-SP. Geousp - Espaço e Tempo (Online), v. 20, n. 1, p. 160$177,2016$.

COLLISCHONN, E.; FERREIRA, C. V. O; SILVEIRA, R. S. 2015. O fator de visão do céu e sua influência sobre as características térmico-higrométricas intraurbanas em Pelotas/RS, Brasil, Geographia Meridonalis, 1(1), p.160-178, 2015.

FERREIRA, C. C. M. Modelo para análise das variáveis de cobertura da terra e a identificação de microclimas, em centros urbanos. Revista Brasileira de Climatologia, Ano 10 - Vol. 14 - JAN/JUL 2014.

FERREIRA, R.V.; MARTINES, M.R.; BUENO, A.C.C.; SIQUEIRA, H.E. Mapa da desvantagem ambiental no município de Uberaba (MG) perímetro urbano. In: XVII Simpósio Brasileiro de Sensoriamento Remoto. Anais.... João Pessoa: INPE, 2015. p. $1731-1737$

HAMMER, Ø. HARPER, D.A.T.; RYAN, P. D. PAST: Paleontological Statistics Software Package for Education and Data Analysis. Palaeontologia Electronica 4(1): 2001. 9pp

HASENACK, $H$. Influência de variáveis ambientais sobre a temperatura do ar na área urbana de Porto Alegre, RS. Dissertação (Mestrado) - Programa de Pósgraduação em Ecologia, UFRGS, 1989.

INSTITUTO BRASILEIRO DE GEOGRAFIA E ESTATÍSTICA. (http://www.cidades.ibge.gov.br/xtras/home.php) (acesso em 10/05/2016).

INSTITUTO BRASILEIRO DE GEOGRAFIA E ESTATÍSTICA. Regiões, mesorregiões geográficas do Brasil. Brasília: IBGE, 2006, v. 34, 62p.

LOMBARDO, M.A. A ilha de calor da metrópole paulistana. Tese (Doutorado) Programa de Pós-graduação em Geografia Física FFCHL/USP, 1984.

MACHADO, L.A.; ASSIS, W.L. Impactos da expansão urbana na porção norte do município de Nova Lima (MG) sobre o clima. Revista do Departamento de Geografia, Volume Especial (2016) 115-132.

MAGALHÃES FILHO, L.C.A.; ABREU, J.F. Ilha de calor urbana, metodologia para mensuração: Belo Horizonte, uma análise exploratória. Revista de Biologia e Ciências da Terra, v.10, n.1, 2010.

MARIANO, Z.; ROCHA, J.R.R. Temperaturas máximas e mínimas absolutas em cidade de pequeno porte: exemplo de Jataí-GO. Revista de Geografia (Recife) V. 33, No. 4, 2016.

MENDONCA F., DUBREUIL V. Termografia de superfície e temperatura do ar na RMC (Região Metropolitana de Curitiba - PR). Revista RA'E GA - O espaço geográfico em analise, n.9, p.25-35, 2005.

MENDONÇA, F.A. O clima e o Planejamento urbano de cidades de Porte Médio e Pequeno: Proposição Metodológica para Estudo e sua Aplicação à Cidade de Londrina/PR. Tese (Doutorado em Geografia Física) - FFLCH/USP, São Paulo, 1995, $298 f$.

MONTEIRO, C.A.F. Teoria e Clima Urbano. São Paulo, 181p. Tese (Livre Docência em Geografia) - Faculdade de Filosofia, Letras e Ciências Humanas, Universidade de São Paulo, 1976. 
MONTEIRO, C.A.F.; MENDONÇA, F.A. Clima Urbano. 2ed. São Paulo: Contexto, 2011.

MOREIRA, E.B.M.; GALVINCIO, J.D. Espacialização das temperaturas à superfície na cidade do Recife, utilizando imagens TM - LANDSAT 7. Revista de Geografia. Recife: UFPE - DCG/NAPA, v. 24, n.3, set/dez. 2007

NASCIMENTO, C. C. Clima e morfologia urbana em Belém. Belém-PA: UFPA, NUMA, 1995. 157p.

NOBREGA, R.S; SANTOS, P.F.C.; MOREIRA, E.B.M. morfologia urbana e ilhas de calor na cidade do Recife/PR: distribuição espacial e intensidade. Revista de Geografia (Recife) V. 33, No. 4, 2016 COLLISCHONN, E. Adentrando a cidade de Pelotas/RS para tomar-Ihe a temperatura. Revista do Departamento de Geografia, Volume Especial 9-23, 2016.

NOVAIS, G.T. Caracterização climática da mesoregião do Triângulo Mineiro/Alto Paranaíba e do entorno da Serra da Canastra (MG). Dissertação (Mestrado) Programa de Pós-graduação em Geografia - Universidade Federal de Uberlândia, UFU, Uberlândia, 2011.

OKE, T.R. Boundary Layer Climates. Second Edition Routleedge, London: Mathuem \& CO, 1987.

OKE, T.R. Inicial guidance to obtain representative meteorological observations at urban sites. Instruments and observing methods, Report n. 81. World Meteorological Organization (WMO). 2016.

OLIVEIRA FILHO, P.C.; MARTINS, K.G.; EVARISTO, G.; ANDRADE, A.R.; DA SILVA, C.A.; MACIEL, A.; BARBOSA, G.D. Análise da influência do uso da terra no microclima urbano: Caso Irati-PR. Floresta e Ambiente, 22(4): 465-471. 2015.

ReboitA, M. S.; RodRIgueS, M.; SILVA, L. F.; ALVES, M. A. Aspectos climáticos do estado de Minas Gerais. Revista Brasileira de Climatologia, ano 11, vol. 17, jul/dez, 2015.

ROCHA, V.M.; FIALHO, E.S. Uso da terra e suas implicações na variação termohigrométrica ao longo de um transeto campo-cidade no município de Viçosa-MG. Revista de C. Humanas, Vol. 10, No 1, p. 64-77, jan./jun. 2010.

ROGERSON, P.A.; CARVALHO, P.F.B. (trad) RIGOTTI, J.I.R. Métodos Estatísticos para Geografia: um guia para o estudante. 3ed. Porto Alegre: Bookman, 2012.

SÁ JUNIOR, A. Aplicação da classificação de Köppen para o Zoneamento Climático do Estado de Minas Gerais. Dissertação (Mestrado) Universidade Federal de Lavras (UFV), Lavras. 2009.

SANCHES, F.; SILVA, R.V.; FERREIRA, R.V.; CAMPOS, C.A.A. Climate Change in the Triângulo Mineiro Region - Brazil. Revista Brasileira de Climatologia, v.21, jul/dez., 2017.

SPIEGEL, M.R. Estatística. 3. ed. São Paulo: Pearson Makron Books/McGraw-Hill doBrasil, 1993.

TARIFA, J. R.; ARMANI, G. Unidades climáticas urbanas. In: TARIFA, J. R.; AZEVEDO, T. R. (Org.). Os climas da cidade de São Paulo: teoria e prática. São Paulo: Pró-reitoria de Cultura e Extensão/Laboratório de Climatologia/FFLCH, 2001. p. 47-70. (Coleção Novos Caminhos, 4.) 
TORRES, F.T.P.; MACHADO, P.J.O. Introdução à Climatologia. São Paulo: Cengage Learning, 2011.

TSO, C.P.; CHAN, B.K.; HASHIM, M.A. An improvement to Energy Balance Model for Urban Thermal Environment Analysis. Energy and Buildings, n. 14, p. 143$152,1990$.

WORLD METEOROLOGICAL ORGANIZATION. Guia de Practicas Hidrológicas: acquisition y proceso de dados. 4ed. N168, Genebra, 1984 